\title{
Increased Accumulation of Medium-Chain Fatty Acids by Dynamic Degradation of Long-Chain Fatty Acids in Mucor circinelloides
}

\author{
Syed Ammar Hussain ${ }^{1,2}{ }^{\circledR}$, Alexis Garcia ${ }^{2}$, Md. Ahsanul Kabir Khan ${ }^{1}$, Shaista Nosheen ${ }^{1}(0$, \\ Yao Zhang ${ }^{1}$, Mattheos A. G. Koffas ${ }^{3}{ }^{(\mathbb{D}}$, Victoriano Garre ${ }^{4}{ }^{(}$, Soo Chan Lee ${ }^{2, *}$ and \\ Yuanda Song ${ }^{1, *}$ \\ 1 Colin Ratledge Center for Microbial Lipids, School of Agriculture Engineering and Food Science, \\ Shandong University of Technology, Zibo 255049, China; ammarshah88@yahoo.com (S.A.H.); \\ akabir08@gmail.com (M.A.K.K.); shaista_nosheen@yahoo.com (S.N.); zhangyao@sdut.edu.cn (Y.Z.) \\ 2 Department of Biology, South Texas Center of Emerging Infectious Diseases (STCEID), University of Texas, \\ San Antonio, TX 78249, USA; alexis.garcia2@utsa.edu \\ 3 Department of Chemical and Biological Engineering, Center for Biotechnology and Interdisciplinary Studies, \\ Rensselaer Polytechnic Institute, Troy, NY 12180, USA; koffam@rpi.edu \\ 4 Departamento de Genética y Microbiología (Unidadasociada al IQFR-CSIC), Facultad de Biología, \\ Universidad de Murcia, 30071 Murcia, Spain; vgarre@um.es \\ * Correspondence: soochan.lee@utsa.edu (S.C.L.); ysong@sdut.edu.cn (Y.S.); \\ Tel.: +1-210-458-5398 (S.C.L.); +86-139-0617-4047 (Y.S.)
}

Received: 30 April 2020; Accepted: 27 July 2020; Published: 5 August 2020

\begin{abstract}
Concerns about global warming, fossil-fuel depletion, food security, and human health have promoted metabolic engineers to develop tools/strategies to overproduce microbial functional oils directly from renewable resources. Medium-chain fatty acids (MCFAs, C8-C12) have been shown to be important sources due to their diverse biotechnological importance, providing benefits ranging from functional lipids to uses in bio-fuel production. However, oleaginous microbes do not carry native pathways for the production of MCFAs, and therefore, diverse approaches have been adapted to compensate for the requirements of industrial demand. Mucor circinelloides is a promising organism for lipid production (15-36\% cell dry weight; CDW) and the investigation of mechanisms of lipid accumulation; however, it mostly produces long-chain fatty acids (LCFAs). To address this challenge, we genetically modified strain M. circinelloides MU758, first by integrating heterologous acyl-ACP thioesterase (TE) into fatty acid synthase (FAS) complex and subsequently by modifying the $\beta$-oxidation pathway by disrupting the acyl-CoA oxidase (ACOX) and/or acyl-CoA thioesterase $(A C O T)$ genes with a preference for medium-chain acyl-CoAs, to elevate the yield of MCFAs. The resultant mutant strains (M-1, M-2, and M-3, respectively) showed a significant increase in lipid production in comparison to the wild-type strain (WT). MCFAs in M-1 (47.45\%) was sharply increased compared to the wild type strain (2.25\%), and it was further increased in M-2 (60.09\%) suggesting a negative role of ACOX in MCFAs production. However, MCFAs in M-3 were much decreased compared to $\mathrm{M}-1$, suggesting a positive role of ACOT in MCFAs production. The M-2 strain showed maximum lipid productivity ( 1800 milligram per liter per day or mg/L.d) and MCFAs productivity ( $1100 \mathrm{mg} / \mathrm{L} . \mathrm{d})$. Taken together, this study elaborates on how the combination of two multidimensional approaches, TE gene over-expression and modification of the $\beta$-oxidation pathway via substantial knockout of specific ACOX gene, significantly increased the production of MCFAs. This synergistic approach ultimately offers a novel opportunity for synthetic/industrial biologists to increase the content of MCFAs.
\end{abstract}


Keywords: Mucor circinelloides; metabolic engineering; acyl-ACP-Thioesterase; acyl-CoA-oxidase; acyl-CoA-thioesterase; $\beta$-oxidation pathway; green biofuels; functional lipids

\section{Introduction}

Over the last two decades, microbially derived oils have offered a platform to face the challenges related to global warming, scarcity of non-renewable recourses, and food security [1-3]. Biokerosene is fundamentally composed of medium-chain-length alkanes that could be easily derived from saturated fatty acids with medium-chain length (MCFAs) [2]. In the current scenario of lowering environmental impact of fossil-fuel, aviation industry is paying a great attention to the development of green-fuels. These fuels have a number of necessities: they must exist as liquid at low temperature and have high energy content by volume. These MCFAs also play a significant role as promising intermediates for the diverse nutraceutical, biochemical, and chemical industries, such as the manufacturing of surfactants, detergents, bio-plasticizers, adhesives, lubricants, perfumes, and precursors for flavor and floral aromas. Furthermore, MCFAs have also been gaining attention in the context of a balanced diet and human health concerns because of their ease of absorption, robust translocation to the liver through the portal veins, and swift metabolism via the $\beta$-oxidation pathway, ultimately enhancing diet-triggered thermogenesis. This mechanism has prompted interest in their use for the prevention and management of different metabolic disorders, such as hypertension, atherosclerosis, hyperlipidemia, type-II diabetes, obesity, and cardiovascular diseases (CVDs). Moreover, the abundance of naturally produced MCFAs from plant sources (i.e., mostly from palm and coconut) has been anticipated to be insufficient to circumvent industrial demand. Thus, the recent focus of investigation has been diverted toward the de novo biosynthesis of MCFAs from diverse oleaginous microorganisms [1,4]. These microorganisms have been genetically manipulated to produce multi-purpose products of biotechnological interest $[5,6]$. Mucor circinelloides Wj11 has an innate ability to accumulate oils up to $36 \%$ of the cell dry weight (CDW) [7]. Owing to its high-oil-generating ability, it offers a reliable option for genetic modulation to produce functional lipids and green energy fuels [8,9]. Previously, these fungal strains have been engineered to produce biofuels and microbial lipids consisting mostly of long alkyl-chains (C14 or more carbons), ultimately making them less attractive for diverse industrial applications $[8,10-17]$. Metabolic engineering of M. circinelloides for the production of MCFAs would facilitate the generation of renewable commodities [4,18].

Fatty acids are produced in the cytosol of $M$. circinelloides through fatty acid synthase-I (FAS-I). These FASs enzymes are indispensable to the organism because they are involved in the fatty acid biosynthetic machinery. The detailed mechanism responsible for acyl-chain length elongation and termination has been elaborated in our recent work [4] and by some other groups [19,20]. In brief, no thioesterase (TE) activity (the key enzyme governing the fate of fatty acid chain length) was detected in fungal FAS-I (PDB ID: 3HMJ) in comparison to the plant and bacterial counterparts. The acyl-chain elongation is terminated by malonyl/palmitoyltransferase (MPT) rather than TE protein $[4,19,20]$. The complete mechanism of fatty acid elongation and termination in geneticallymodulated fungal FAS is depicted in Figure 1. 


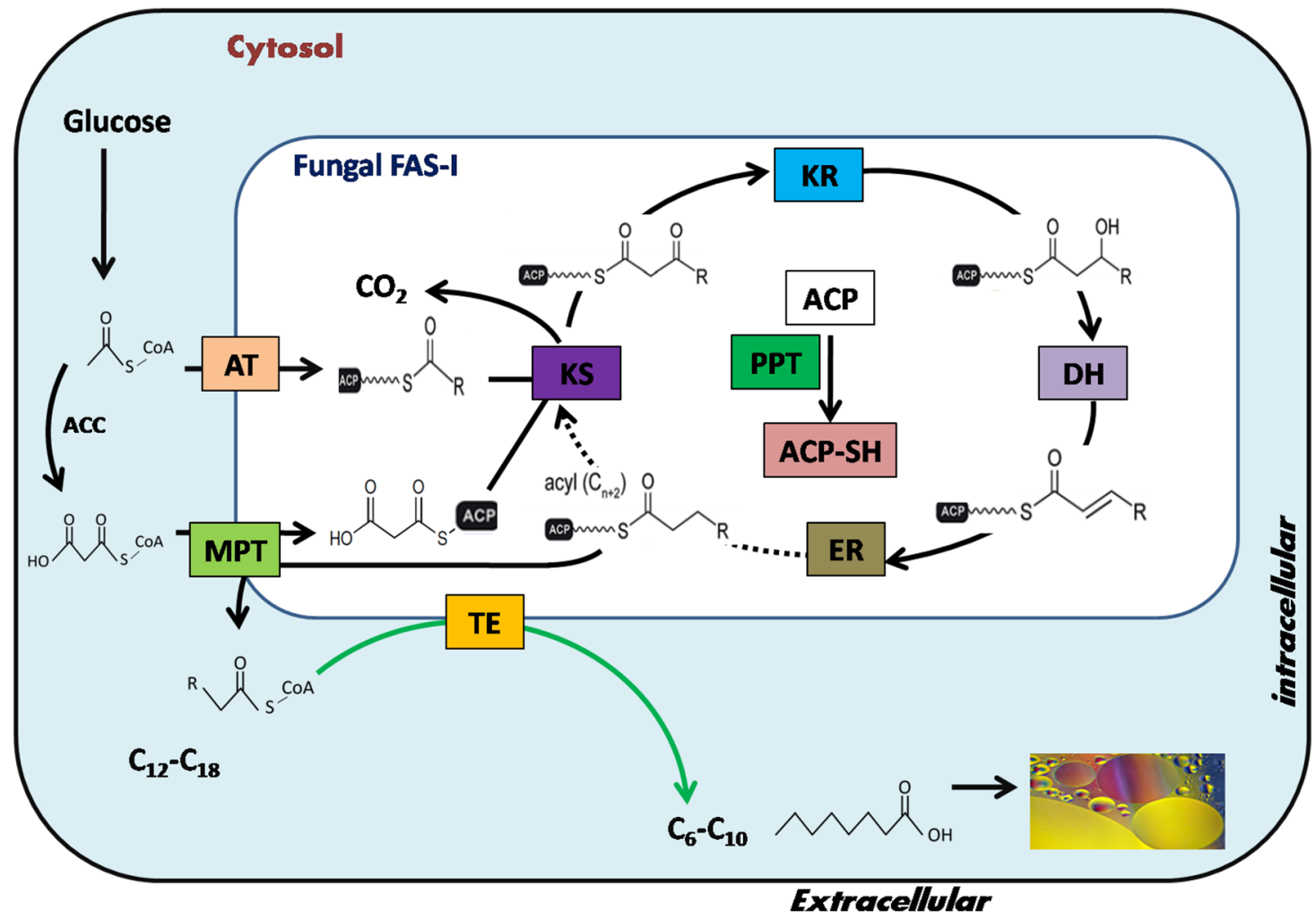

Figure 1. Design and strategy for engineering fungal fatty acid synthase (FAS) in TE-over-expressing strains of Mucor circinelloides MU758 to overproduce medium-chain fatty acids (MCFAs) contents. Reaction cycles catalyzed by engineered fungal FASs. A heterologous acyl-ACP-thioesterase (TE) was integrated into fatty acid synthases (FASs) to release MCFAs (represented by the green arrow). Functional domains are arranged according to reaction sequence. AT: acetyltransferase; KS: ketoacyl synthase; KR: ketoacyl reductase; DH: dehydratase; ER: enoyl reductase; MPT: malonyl/palmitoyltransferase; ACP: acyl carrier protein; PPT: phosphopantetheinyl transferase; ACC: acetyl-CoA carboxylase.

In addition to the distinctive molecular configuration and mechanism of fungal FASs action, the $\beta$-oxidation pathway also plays a pivotal role in the plant, fungal and animal kingdoms [21]. In fungi and plants, fatty acid oxidation is executed exclusively in peroxisomes [22]. Peroxisomal $\beta$-oxidation enables fungi to degrade long and MCFAs for eventual utilization of acetyl-CoA as the sole carbon and energy source for growth. This pathway is intimately coupled to break down both extracellular and intracellular fatty acids originating from outside source and FAS pathway $[23,24]$. The detailed mechanism of fatty acid catabolism in the genetically manipulated peroxisome is illustrated in Figure 2. Previously, various approaches have been adopted in different microorganisms to improve the contents of MCFAs, such as engineering to disrupt/reverse the $\beta$-oxidation pathway in Escherichia coli and Saccharomyces cerevisiae; diverse genetic modulation ofmulti-dimensional proteinsrecognized as FASs in Yarrowia lipolytica, S. cerevisiae, and E. coli by modification of the keto-synthase (KS) and acetyl-transferase (AT) binding sites; and tailoring of the magnitude of the KS active pockets and ACP-acyl chain binding sites and incorporating of domain swapping of malonyl-palmitoyl transferase (MPT) with TE protein. Taken together, the aforesaid investigations have reported a low-abundance of MCFAs, and some depend on the addition of specific fatty acids in the culture medium [24-29]. Moreover, most oleaginous microorganisms naturally generate mostly long-chain (16 and 18-carbon) fatty acids (LCFAs), which are attributed to the preferential activities of transacylases and acyl-ACP-thioesterases toward a longer acyl-AC chain length $[30,31]$. Furthermore, these microorganisms have no natural affinity to produce MCFAs due to the absence of MCFAs-producing pathways. However, there is an increasing demand for MCFAs production as a substrate for the functional food and jet-fuel industries, due to their 
unique physiochemical characteristics [3,5,6,18,32-44]. To address the above-discussed challenges, there is an immediate need for the selection of an appropriate oleaginous microorganism and suitable strategy/tool. Therefore, in the current investigation, we employed a novel synergistic approach to overproduce MCFAs contents. To achieve our aim, an optimized lipid-tailoring heterologous TE protein from our recent investigation (M65 is uracil auxotroph of M. circienlloides Wj11) [4] was first integrated into strain MU758 (uracil and leucine auxotroph strain) into native fungal FAS, followed by modification of the peroxisomal $\beta$-oxidation pathway by disruption of the gene encoding acyl-CoA oxidase $(A C O X)$ protein with a substrate preference for medium-chain acyl-CoAs. The latter approach was adopted to sustain the oxidation of LCFAs and to avert the oxidation of MCFAs (Figure 2). We screened high lipid producer mutants that demonstrated the required fatty acid portfolio (i.e., $\mathrm{C} 8$ to $\mathrm{C} 12$ ). Furthermore, the ACOT gene, exhibiting a substrate preference for the hydrolysis of medium-chain CoAs, was also disrupted to verify its involvement in fatty acid breakdown into free fatty acids, as well as the transportation of MCFAs out of peroxisomes. This combinatorial methodology proves an excellent opportunity to produce MCFAs in high abundance.

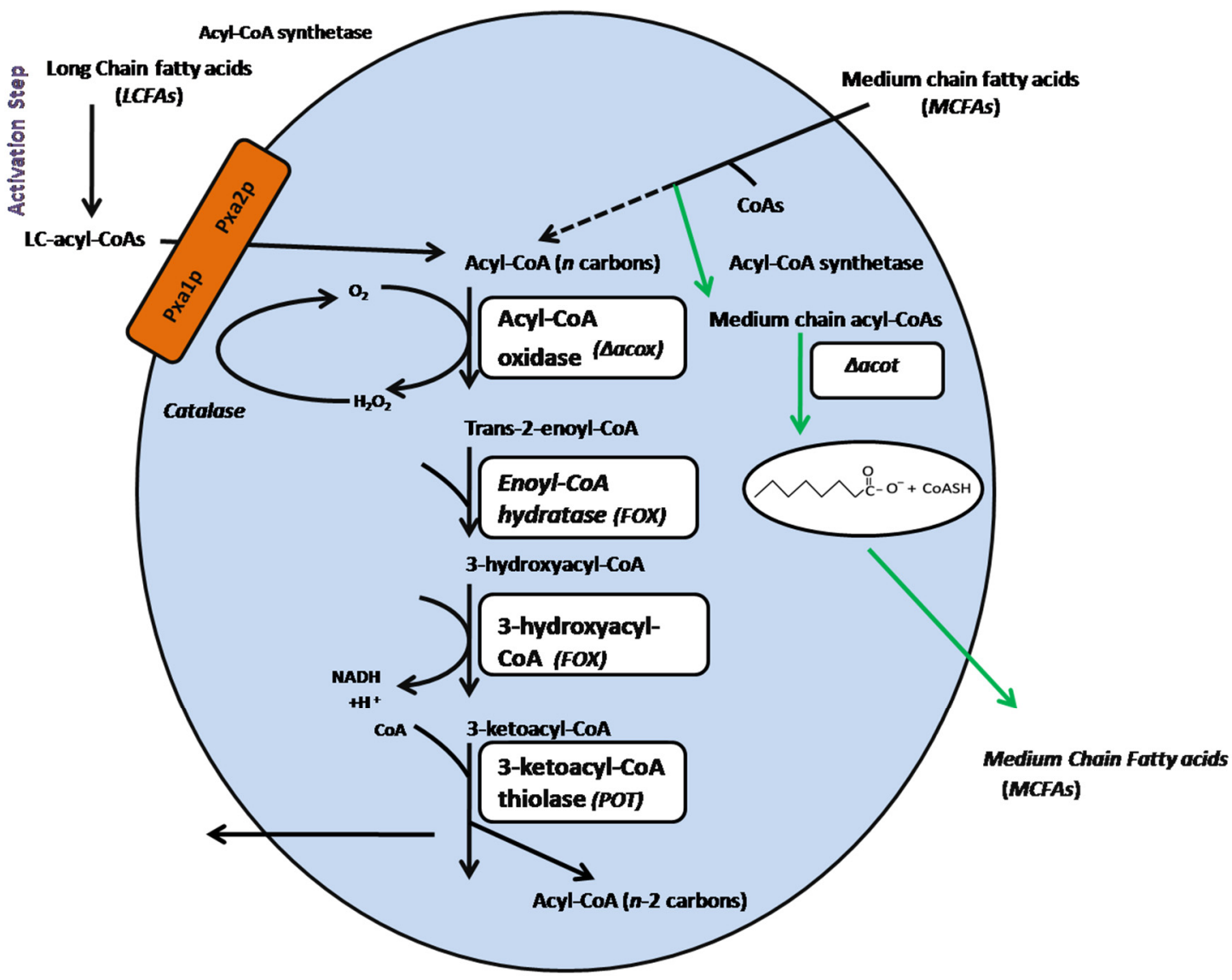

Modified peroxisomal $\beta$-oxidation Pathway

Figure 2. Modification of the $\beta$-oxidation pathway in Mucor circinelloides strain MU758 (model adapted from Chen et al. [24]). The black lines (solid + dashed) represent the original pathways for long and medium-chain fatty acid degradation steps in peroxisomes. The green line demonstrates the possible route for MCFAs in peroxisomes after disruption of the ACOX gene (i.e., exhibiting specificity for medium chain acyl-CoAs) (i.e., M-2). The ACOT gene was also disrupted (in the case of M-3), which has a substrate preference for catalyzing the hydrolysis step for acyl-CoA molecules into free fatty acids (FFAs) and coenzyme A (CoAs), eventually facilitating the outward-transportation event in peroxisomes by specific transporters (not shown). 


\section{Material and Methods}

\subsection{Strains, Plasmids, Cultivation, and Transformation Conditions}

The strains and plasmids used in the current investigation are listed in Table 1. For sporulation, M. circinelloides strain MU758 (i.e., the uracil and leucine auxotroph strain MU758, which has comparatively similar oil-producing/physiological characteristics to M. circinelloides WJ11 [7], was allowed to grow on YPG medium (yeast peptone glucose agar: $3 \mathrm{~g} / \mathrm{L}$ yeast extract, $20 \mathrm{~g} / \mathrm{L}$ glucose, $10 \mathrm{~g} / \mathrm{L}$ peptone, $2 \%$ agar, $\mathrm{pH} 4.5$ ) at $26{ }^{\circ} \mathrm{C}$ in the light for $3 \mathrm{~d}$. The medium was supplemented with $200 \mu \mathrm{g} / \mathrm{mL}$ uridine as needed. Subsequently, for spore collection, $8.5 \% \mathrm{NaCl}$ solution was added to each Petri plate, and the spores were gently scraped with a glass spreader. For the transformation experiments, spore counting was carried out with a hemocytometer. Transformation was carried out using an electroporation-mediated procedure as previously described by Lee et al. [45]. Minimal medium with casamino acids (MMC) ( $\mathrm{pH}$ 3.2) containing $0.5 \mathrm{M}$ sorbitol was used for transformation experiments [4,46-50]. M. circinelloides pores are multinucleate in nature. Thus, to segregate the homokaryotic transformants, the vegetative selection protocol was carried out by growing the heterokaryotic transformants on MMC ( $\mathrm{pH} 4$.5) medium to produce homokaryotic transformants. To select mutants that impulsively eliminate the pyrF marker gene (encodes for uracil biosynthesis), 5-fluoroorotic acid (2.5 mg/mL) was added to the YPG medium [49]. All the mutant (i.e., Mu-TE+, the strain harboring the TE-over-expressing plasmid, hereafter referred to as $\mathrm{M}-1 ; \mathrm{Mu}-\mathrm{TE}+,[\operatorname{acox} \Delta]$, the strain harboring the TE-over-expressing plasmid and exhibiting the disrupted allele for the $A C O X$ gene, hereafter referred to as M-2; and Mu-TE+ $[a \operatorname{cox} \Delta, a \cot \Delta]$, the strain harboring the TE-over-expressing plasmid and exhibiting the disrupted allele for ACOX and ACOT genes, hereafter referred to as M-3) and the wild-type (used as the control, hereafter referred to as WT) strains of M. circinelloides (MU758) were initially cultivated by using $80 \mu \mathrm{L}$ spore suspension $\left(\sim 10^{7}\right.$ spores $\left./ \mathrm{mL}\right)$ in 1.0-L flasks containing $150 \mathrm{~mL}$ of Kendrick and Ratledge medium (K and R); $30 \mathrm{~g} / \mathrm{L}$ glucose, $3.3 \mathrm{~g} / \mathrm{L}$ diammonium tartrate, $7.0 \mathrm{~g} / \mathrm{L} \mathrm{KH}_{2} \mathrm{PO}_{4}, 2.0 \mathrm{~g} / \mathrm{L} \mathrm{Na}_{2} \mathrm{HPO}_{4}, 1.5 \mathrm{~g} / \mathrm{L} \mathrm{MgSO} \cdot 7 \mathrm{H}_{2} \mathrm{O}, 1.5 \mathrm{~g} / \mathrm{L}$ yeast extract, $0.1 \mathrm{mg} / \mathrm{L} \mathrm{CaCl} 1_{2} \cdot 2 \mathrm{H}_{2} \mathrm{O}, 8 \mathrm{mg} / \mathrm{L} \mathrm{FeC1}{ }_{3} \cdot 6 \mathrm{H}_{2} \mathrm{O}, 1 \mathrm{mg} / \mathrm{L} \mathrm{ZnSO} \cdot 7 \mathrm{H}_{2} \mathrm{O}, 0.1 \mathrm{mg} / \mathrm{L} \mathrm{CuSO}{ }_{4} \cdot 5 \mathrm{H}_{2} \mathrm{O}, 0.1 \mathrm{mg} / \mathrm{L} \mathrm{CO}$ $\left(\mathrm{NO}_{3}\right) \cdot 6 \mathrm{H}_{2} \mathrm{O}$ and $\left.0.1 \mathrm{mg} / \mathrm{L} \mathrm{MnSO} 4 \cdot 5 \mathrm{H}_{2} \mathrm{O}, \mathrm{pH} 6.0\right)[4,9,16,17,51-53]$. Subsequently, these flasks were equipped with baffles to improve aeration and finally placed in a shaker at $150 \mathrm{rpm}$ at a temperature of $26{ }^{\circ} \mathrm{C}$ for $24 \mathrm{~h}$. the resultant seed culture was used for inoculation at $10 \%(v / v)$ into a 5-L fermenter (BioFlo/CelliGen 120, New Brunswick Scientific, Edison, NJ, USA) containing 1.5 L of modified K and $\mathrm{R}$ medium (i.e., $80.0 \mathrm{~g}$ glucose/L plus inorganic salts, $2.0 \mathrm{~g}$ diammonium tartrate). The fermenters were adjusted at $26^{\circ} \mathrm{C}$ and stirred at $700 \mathrm{rpm}$ with aeration at $0.5 \mathrm{vvm}$. The $\mathrm{pH}$ of the culture medium was constantly adjusted to 6.0 by means of auto-control addition of $2.0 \mathrm{M} \mathrm{H}_{2} \mathrm{SO}_{4} / 2.0 \mathrm{M} \mathrm{NaOH}$ solutions. Culture samples of mutant and control strains were collected for a pre-specified duration for further analysis (i.e., 12, 24, 36, 48, 60, 72, 84, $96 \mathrm{~h}$ ) based on the of lipid accumulation characteristics [4,54].

Table 1. List of strains and plasmid used in this investigation.

\begin{tabular}{|c|c|c|c|}
\hline & Name & Genotype/Characteristics & References \\
\hline \multirow[t]{5}{*}{ M. circinelloides } & MU758 & LeuA-pyrF & This work \\
\hline & MYS719 & LeuA $A^{+}$pyrF $F^{-} T E+$ & This work \\
\hline & MYS721 & LeuA ${ }^{+} p y r F^{+} T E+a \operatorname{cox} \Delta:: d p l 237$ & This work \\
\hline & MYS722 & $\mathrm{LeuA}^{+}$pyrF $F^{+} \mathrm{TE}+\operatorname{acox} \Delta:: d p l 237$ & This work \\
\hline & MSA321 & $\operatorname{LeuA}^{+}$pyrF ${ }^{+} \mathrm{TE}+a \operatorname{cox} \Delta:: d p l 237$ acot $\Delta:: p y r F$ & This work \\
\hline \multirow{5}{*}{ Plasmids } & pMAT1552-LeuA TE & Contain LeuA Marker gene and thioesterase gene (TE) & This work \\
\hline & pCR21-TOPO & Ampicillin ${ }^{\mathrm{R}}$ Kanamycin $^{\mathrm{R}}$ & Invitrogen \\
\hline & pTOPO-pyrF & 890-bp pyrF fragment cloned into pCR21-TOPO & This work \\
\hline & pACOX-KO & ACOX disruption construct cloned into pCR21-TOPO & This work \\
\hline & pACOT-KO & ACOT disruption construct cloned into pCR21-TOPO & This work \\
\hline
\end{tabular}




\subsection{Construction of the Thioesterase (TE) Over-Expressing Plasmid}

The acyl-ACP thioesterase (TE) gene was cloned into vector pMAT1552-LeuA [4,9] for expression in the M. circinelloides strain (MU758). The aforesaid vector carried the LeuA gene from M. circinelloides flanked by approximately $1.0 \mathrm{~kb}$ of the up- and downstream sequences of the carRP-carRP locus (Figure 3). This plasmid was used for the construction of the TE-over-expression vector, as previously described by Zhang et al. [9]. In brief, this vector contains a strong promoter (i.e., Pgpd-1 (accession No.: AJ305345), the LeuA gene (encodes for leucine biosynthesis) as a selectable marker; the surrounding sequences analogous to the flanking sequence of the carotenogenic gene (i.e., carRP-carRP locus) facilitate chromosomal integration via homologous recombination (HR). The TE gene was amplified from the genome of Umbellularia californica (GenBank accession No.: KR180394) by PCR with specific primer pairs (Supplementary Materials: Table S1). The primers contained sequences (30 bp) flanking the restriction site XhoI. The resulting PCR fragment was finally cloned into an expression vector (i.e., pMAT1552-LeuA). The restriction endonucleases enzyme XhoI was to generate the mutant plasmid designated as pMAT1552-LeuA-TE (One-Step Cloning Kit from Takara Bio USA, Inc., Mountain View, CA, USA). All primers used for plasmid construction and gene conformation are listed in Supplementary Table S1.

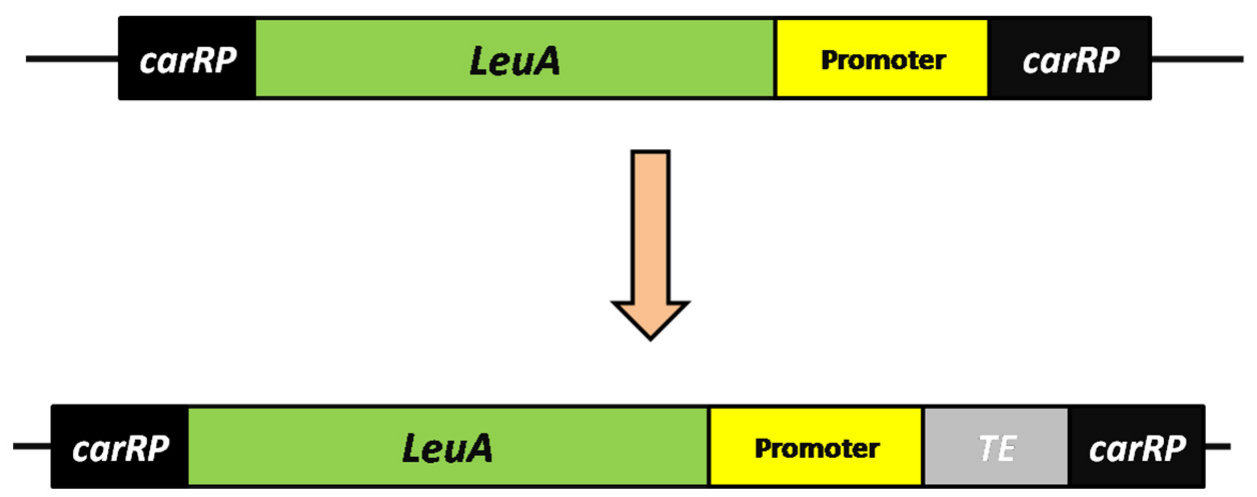

Figure 3. Expression of the TE gene. The structure of plasmid pMAT1552-LeuA-TE for TE gene over-expression in M. circinelloides (MU758) is shown. The grey box indicates the coding region of the acyl-ACP-thioesterase (TE) gene, while the green rectangle of LeuA gene indicates a selectable marker, and the flanking sequences correspond to regions surrounding the carotenogenic carRP gene (black boxes) to allow its chromosomal integration by homologous recombination.

\subsection{Construction of a Green pyrF Marker}

To construct the pyrF recyclable marker, the DNA fragment (890 bp) carrying the pyrF gene was amplified from the genomic DNA of M. circinelliodes (MU758) using a specific primer pair (YS-275 and YS-276). Subsequently, the previously constructed plasmid pSL13 [55] was used for amplification of the 237bp DNA fragment containing overhanging XbaI or Not I restriction enzyme recognition sites with primers (YS-277 to YS-280) (Supplementary Table S2), which were flanked by overhanging XbaI or NotI restriction enzyme recognition sites. All three fragments were joined by overlapping PCR (YS-281 to YS-282) to develop the cassette $(1910 \mathrm{bp})$. Finally, the resulting cassette was cloned into the TOPO vector to generate plasmid pYS719 (Table 1), which harbors a DNA cassette with 237 bp direct repeats on both sides of the pyrF gene (Figure $4 \mathrm{~A}$ ). 
A

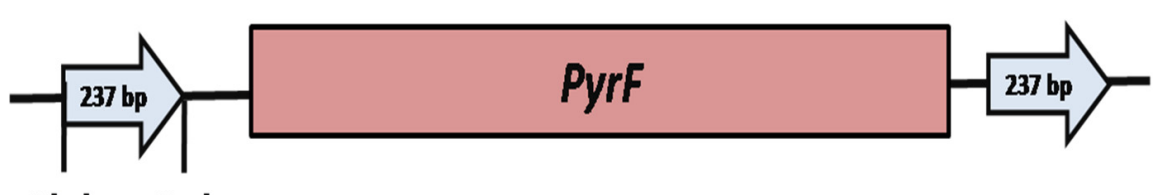

Xbal Notl

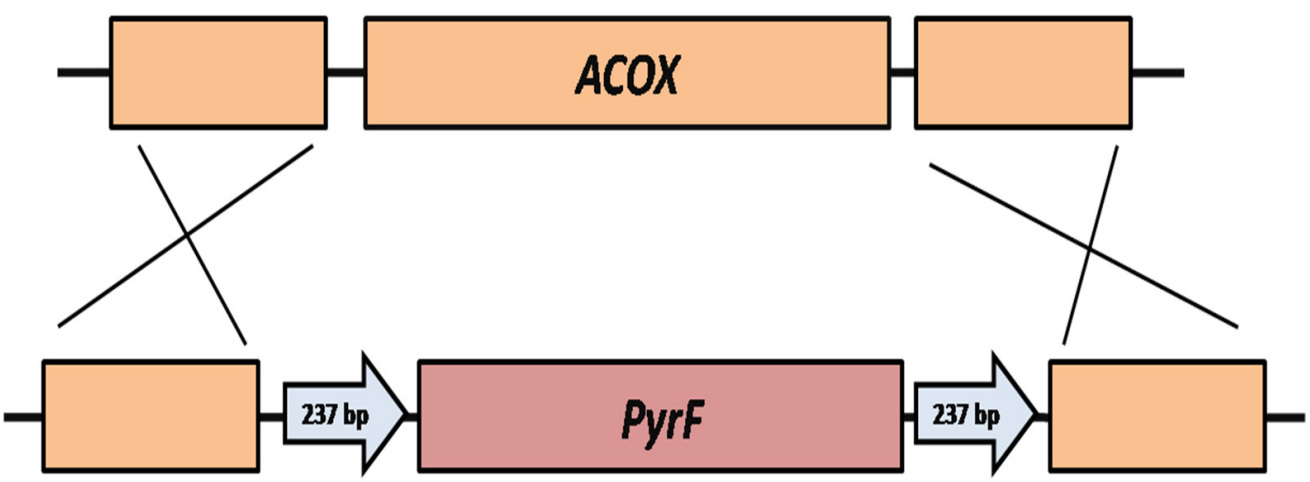

B

TE-overexpressing strain (M-1)

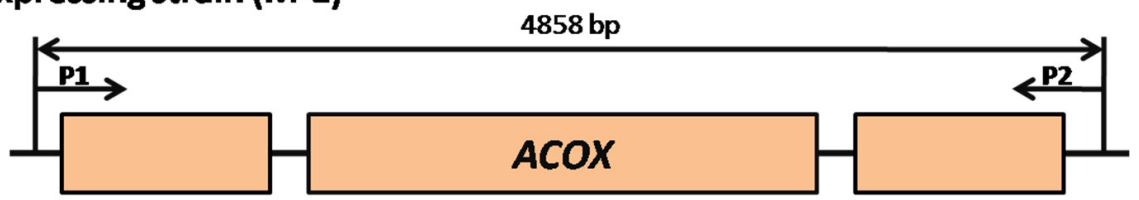

ACOXA::pyrF-dpl237 (M-2)

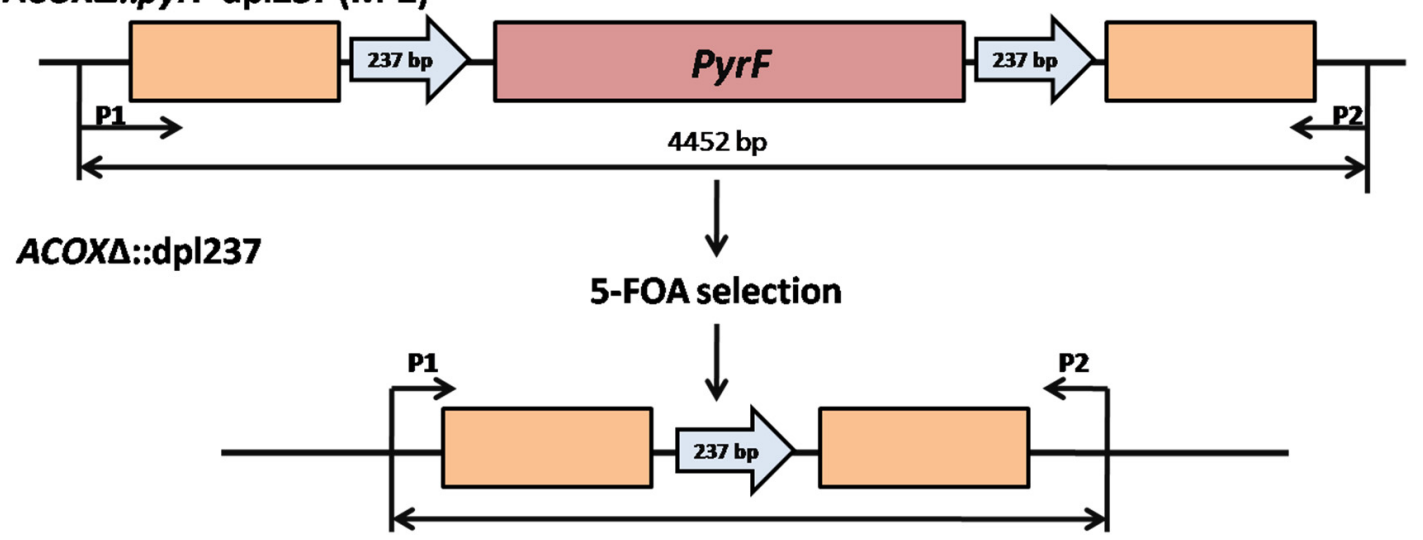

Figure 4. Disruption of the $A C O X$ gene and confirmation of the excision of the pyrF marker. (A) Homologous replacement of the ACOX gene with the pyrF recyclable marker. (B) Confirmation of the excision of the pyrF marker. Strain MYS720 (acox $\Delta:: p y r F-d p l 237)$ was inoculated on yeast peptone glucose agar (YPG) medium containing 5-FOA. After $3 \mathrm{~d}$ of incubation, spontaneous resistant mutants emerged to form a sector from the colony (data not shown). The 5-FOA resistant mutants underwent a vegetative cycle on YPG medium containing 5-FOA. The obtained spores were subjected to polymerase chain reaction (PCR) analysis and auxotrophy tests. Excision of the pyrF marker from the acox $\Delta:: p y r F-d p l 237$ allele was confirmed by PCR (see details in Section 2.5). The strains with the excised pyrF marker did not grow on media without leucine. Two independent (acox $\Delta:: d p l 237)$ strains were obtained. 


\subsection{Disruption of the ACOX and ACOT Genes}

The M. circinelloides strain contains many acyl-CoA oxidase (ACOX) and acyl-CoA thioesterase (ACOT) genes with diverse substrate preferences [7]. Based on BLAST analysis, we selected the ACOX gene (scaffold00025.39), which has a significant resemblance index to the ACX3 gene (Gene ID: 837140) from Arabidopsis thaliana (substrate specificities for medium acid fatty acids) [56] and the ACOT gene (scaffold00002.31), which is a homolog of mouse ACOT5 (Gene ID: 217698) (substrate specificities for medium chain acyl-CoAs) [57]. To knockout the ACOX gene, we assembled a knockout (KO) cassette comprising the pyrF blaster marker ( $p y r F-d p l 237$ ) flanked by $\sim 1 \mathrm{~kb}$ of $5^{\prime}$ and $3^{\prime}$ up- and downstream regions of the ACOX gene through overlapping PCR. The $5^{\prime}$ and $3^{\prime}$ regions were amplified with the primers (YS-310, YS-311 and YS-312, YS-313, respectively). Genomic DNA of M. circinelloides MU758 strain was used as a template. The pyrF blaster (containing the $d p l 237$ on either side) marker was amplified by utilizing the primer (AS-719 and AS-720). To generate a disruption allele, the following three fragments (50 ng of each fragment) were joined by overlapping PCR using the nested forward and nested reverse primers YS-314 and YS-315. The resulting KO cassette was cloned into the TOPO vector by using the Invitrogen kit according to manufacturer's instructions with slight modifications.

To disrupt the ACOX gene, the bacterial strain was cultured overnight at $37{ }^{\circ} \mathrm{C}$ at $200 \mathrm{rpm}$. The plasmid containing the $\mathrm{p} A C O X-\mathrm{KO}$ cassette was extracted using the Zymo Research Miniprep kit (Irvine, CA, USA) according to manufacturer's guidelines. The restriction enzyme (Biolab-England) was used to generate the linear fragment required for the ACOX-KO cassette. The aforesaid cassette $(\sim 3 \mu \mathrm{g})$ was introduced into the MU758 strain using the electroporation-mediated method as previously described by Lee et al. [58] to eventually obtain the MYS721 and MYS722 mutant strains (Table 1, Figure 4A,B). To evaluate the functionality of the ACOT gene, we further proceeded to disrupt the aforesaid gene in the $A C O X$ mutant strains (i.e., acox $\Delta:: d p l 237)$. To achieve this goal, a PCR product of the ACOT disruption cassette was obtained from plasmid pACOT-KO with primers pairs YS-381 and YS-382 using DreamTaq DNA polymerase (Thermo Scientific, Agawam, MA, USA). Subsequently, the ACOT disruption cassette was introduced into the strain MYS722 (acox $\Delta:: d p l 237$ ) (Figure 4) using our previously described method [49,54]. From 24 independent transformations, we screened seven mutants displaying the required phenotype in comparison to the control and wild-type strain. Two independently obtained mutants, MSA321 and MSA322 (acox $\Delta:: d p l 237$ acot $\Delta:: p y r F)$ (Table 1), were selected for further analysis.

\subsection{Excision of the pyrF Gene from the pyrF Blaster Marker}

Spores of strain MYS720 (acox::pyrF-dpl237) were grown on YPG medium containing 5-FOA $(2.5 \mathrm{mg} / \mathrm{mL})$ and uridine to select mutants that still produced positive colonies but required uridine for growth. The candidate mutants were passaged on YPG medium containing uridine and 5-FOA. Excision of the pyrF gene was verified by PCR.

\subsection{Preparation for Genomic DNA and Quantitative Reverse Transcription Polymerase Chain Reaction (qRT-PCR) Analysis}

To confirm the genetic modification, all the mutant strains were allowed to grow on liquid $\mathrm{K}$ and $\mathrm{R}$ medium for $3 \mathrm{~d}$ (under light at $28^{\circ} \mathrm{C}$ and $150 \mathrm{rpm}$ ). Subsequently, the mycelia were collected by passage through suction filtration assembly. The resulting mycelia were washed twice to remove all possible medium contents. Finally, the genomic DNA was extracted using the DNA quick Plant System Kit (Tiangen Biotech Beijing, Co., Ltd., Beijing, China) according to the manufacturer's instructions. All the genomic manipulation was confirmed using the PCR amplification protocol with the primers mentioned in Supplementary Table S1. For qRT-PCR analysis, all the mutant (i.e., M-1, M-2, and M-3) and control strain (WT) used in current study were grown in a 5.0-L fermenter with modified $\mathrm{K}$ and $\mathrm{R}$ medium. Subsequently, the mycelia were harvested at the pre-specified time points of 24, 48, and $72 \mathrm{~h}$. For quantitative reverse transcription PCR (qRT-PCR) analysis, the mutant strains (i.e., M-1, M-2, and M-3) and the wild-type strain (WT) were grown in a 5.0-L fermenter with modified K and R 
medium, and the mycelia was harvested at 24, 48, and $72 \mathrm{~h}$. Total RNA and qRT-PCR analysis were carried out as previously described method by Zhang et al. [9] using primers (Supplementary Materials: Table S3). The transcriptional level of all the targeted genes were normalized to the levels of $18 \mathrm{~S}$ rRNA mRNA. The results were represented as the comparative expression level, calculated using the $2^{-\Delta \Delta \mathrm{Ct}}$ method.

\subsection{Determination of Cell Dry Weight (CDW) and Lipid Accumulation}

The biomass of all strains (i.e., mutants and control) was collected using the vacuum filtration method. The resulting biomass was washed three times with distilled water to remove all medium contents and then frozen at $-80{ }^{\circ} \mathrm{C}$ for $3.0 \mathrm{~h}$ prior to lyophilization. To calculate the cell dry weight (CDW), the gravimetrical method was used. Lipid extraction was executed as previously described by Folch et al. [59]. Fatty acid methyl ester (FAME) preparation and GC/MS conditions were performed as described in our previous investigations [4,9].

Lipid productivity $\left(P_{\text {Lipid }}\right)$ and MCFA productivity $\left(P_{\text {MCFA }}\right)$ were calculated as follows:

$$
\begin{gathered}
P_{\text {Lipid }}(\mathrm{mg} / \mathrm{L} \text { day })=\left(\mathrm{C}_{f} \times C D W_{f}-\mathrm{C}_{i} \times C D W_{i}\right) /\left(T_{f}-T_{i}\right) \\
P_{M C F A}(\mathrm{mg} / \mathrm{L} \text { day })=\left(\mathrm{C}_{M C F A}(\mathrm{mg} / \mathrm{mg} \mathrm{TL}) \times \operatorname{Lipid}(\mathrm{mg} / \mathrm{L}) /(T \text { (day })\right)
\end{gathered}
$$

where $C_{f}$ is the final lipid content $(\mathrm{mg} / \mathrm{L}), C_{i}$ is initial lipid content, $T_{f}$ is the harvesting time (day) and $T_{i}$ is the cultivation time (day), $\mathrm{CDW}_{f}$ and $\mathrm{CDW}_{i}$ are the initial and final cell dry weight $(\mathrm{mg} / \mathrm{L})$, and TL is the total lipid content.

\subsection{Determination of Glucose and Nitrogen Concentration in the Culture Medium}

To measure the glucose concentration in the culture, the Glucose oxidase-Perid-test kit (Shanghai Rongsheng Biotech Co., Ltd., Shanghai, China) was used, while the indophenol method was used according to Chaney and Marbach [60] to calculate the ammonium concentration.

\subsection{Separation of Lipid Classes}

To estimate the quantity of diverse lipid classes in the engineered strains, total lipids (TLs) were fractioned into their primary components as previously described in our recent investigation [4]. Hydrated florisil (7\%) acquired by shaking overnight at room temperature was ultimately used as an adsorbent for the chromatography. Total lipids (TLs) extracted from $50 \mathrm{~mL}$ of fungal culture were loaded onto the column, and fractions were eluted in the following solvents ratios: 95:5 hexane/ether, 85:15 hexane/ether, 75:25 hexane/ether, 50:50 hexane/ether, 98:2 ether/methanol, and 96:4 ether/acetate to elute off free fatty acids (FFA), triacylglycerides (TAGs), diacylglycerides (DAGs), monoacylglycerides (MAGs), sterols, and steryl esters, respectively, by using the method as described by Carroll [61].

Abundance of lipid in collected eluents was computed by dichromate reduction procedure as described by Freeman and West [62]. In brief, samples were collected and make completely dry before further analysis. Each dried sample was resuspended in $1.0 \mathrm{~mL}$ of $0.2 \%$ potassium dichromate dissolved in $96 \%$ sulfuric acid $\left(\mathrm{H}_{2} \mathrm{SO}_{4}\right)$ and boiled for $15 \mathrm{~min}$. Samples were subjected to cool down, and a more $1.0 \mathrm{~mL}$ of water was added. Samples were again allowed to cool, and their absorbance was measured at $440 \mathrm{~nm}$ to detect formation of $\mathrm{Cr}^{3+}$.

\subsection{Statistical Analysis}

A statistical analysis of the obtained data was performed using SPSS 16.0 for Windows (SPSS Inc., Chicago, IL, USA). Differences between means were calculated by the Student's $t$ test, and $p<0.05$ was regarded as significantly different. The mean value and standard error of the mean were computed from the data obtained from three independent experiments. 


\section{Results}

\subsection{Generation of Heterologous Acyl-ACP Thioesterase (TE) Gene-Over-Expressing Strains}

The TE-over-expressing strain (i.e., M-1) was generated to evaluate the role of MCFAs production and lipid accumulation. We chose the best heterologous TE protein from the genome of $U$. californica based on our previous study [4] and inserted it into the expression vector pMAT1552-LeuA. (Figure 3 and Supplementary Table S1, Figure S1) (see Section 2.2 for details). Finally, lipid overproducing mutant strains (M-1) were selected for further genetic manipulation experiments.

\subsection{Generation of the pyrF Blaster Marker and Disruption of the Acyl-CoA Oxidase (ACOX) and Acyl-CoA} Thioesterase (ACOT) Genes in the TE-Over-Expressing and acox $\Delta::$ dpl237 Mutant Strains

We sequentially proceeded to disrupt the genes encoding the ACOX and ACOT proteins in the TE-over-expressing and acox $\Delta:: d p l 237$ mutant strains to assess the function of the pyrF blaster marker. To achieve our aim, we first targeted the gene encoding acyl-CoA oxidase (ACOX) protein, which has a preference for the medium-chain acyl-CoA substrate in the TE-over-expressing strain (i.e., M-1). Complete loss of the ACOX gene resulted in reduced growth in comparison to the control strain, ultimately confirming the negative effect of the genetic modification on fungal cells (i.e., M-2) (Figure 4A). Transformation and positive colony selection were carried out according to the method described by Rodríguez-Frómeta et al. [8]. To obtain stable mutants with enriched recombinant nuclei, the mutant strains were subjected to three rounds of vegetative growth. Finally, we used the stable mutant strain, (i.e., M-2) MYS-719 (acox $\Delta:: p y r F-d p l 237)$ to assess the efficiency of the recyclable $p y r F$ marker (Figure 4B, Supplementary Figure S2).

To further confirm the disruption of the ACOX gene, we grew spores of the mutant strain MYS-719, which contains only the acox $\Delta$ allele instead of the wild type allele. Primers YS-351(P1) and YS-352 (P2) (Supplementary Table S1) outside of the KO cassette were employed to verify the genotype of the progeny. A PCR fragment of $4858 \mathrm{bp}$ was produced from the wild type ACOX allele, while a $4452 \mathrm{bp}$ fragment was obtained from the acox $\triangle$ allele, eventually validating the absence of the wild-type $A C O X$ allele in strain MYS-719 (Figure 4B, Supplementary Table S3).

Finally, we disrupted the ACOT gene (which functions in the hydrolysis of medium-chain acyl-CoAs in peroxisomes) in the strain M-2 background to evaluate the efficiency of the recyclable/green marker and to verify the involvement of ACOT protein in medium-chain acyl-CoA breakdown and transportation out of peroxisomes. To achieve this goal, strain MYS-721 (i.e., M-2) was subjected to the transformation procedure to disrupt the ACOT gene (Figure 5). Transformation and positive colony selection were carried out according to our previously described method [54]. We screened 21 transformants from 24 independent transformations by PCR amplification using primer pairs YS-381, YS-353, YS-354, and YS-382 (Supplementary Table S1), which underwent three cycles of vegetative passage as previously described for strains M-1 and M-2. The resultant stable strains, MSA321 and MSA322 (i.e., M-3), validated the efficiency of the recyclable pyrF blaster marker as well as its utility for a series of gene deletions in $M$. circinelloides MU758 (Supplementary Figure S2A,B). Disruption of the ACOX and ACOT genes was also verified by qRT-PCR analysis. 
A

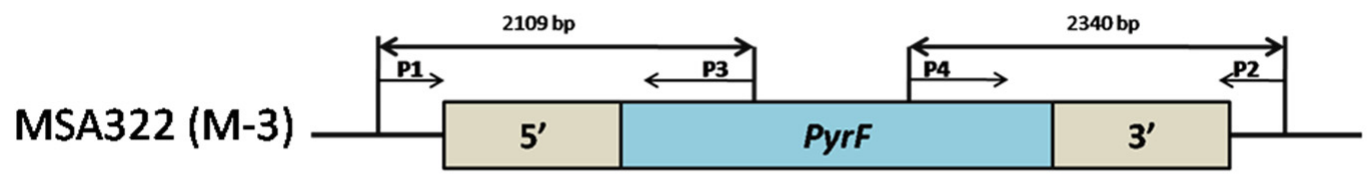

MYS722 (M-2)

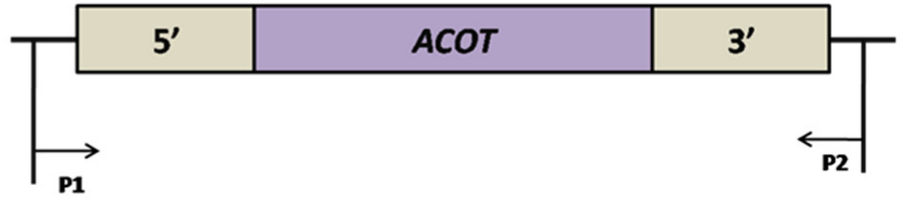

B

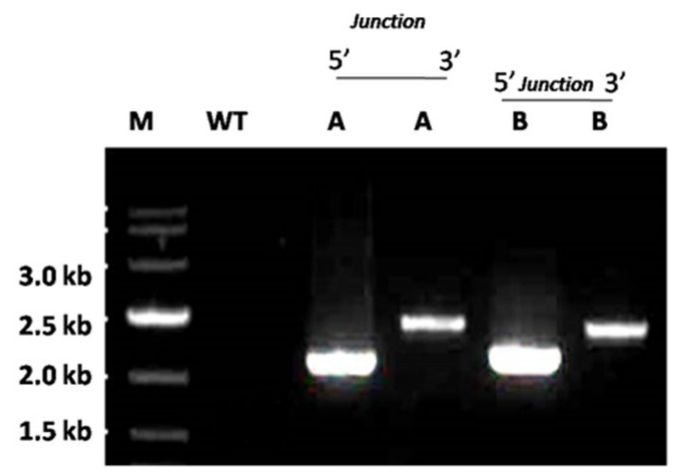

Figure 5. Confirmation of ACOT gene knockout in the mutant strains (i.e., M-3); MSA322 (A) The acot $\Delta:: p y r F$ allele was verified by junction PCR. P1 and P2 primers recognize the sequences outside of the disruption construct. P3 and P4 primers only recognize the pyrF gene marker. P1: YS-381; P2, YS-353; P3, YS-354; P4, YS-382 (Supplementary Table S1). (B) 5' and 3' junction PCR verify the disruption of the ACOT gene, where primers P1 and P2 amplify $2109 \mathrm{bp}$ fragment in the mutant strains MYS722 while in the WT the same primers do not amplify the fragment. This outcome confirms the ACOT gene was swapped with the pyrF gene in the mutant strains, M-3; (MSA322).

3.3. Expression Levels of Acyl-ACP-Thioesterase (TE), Acyl-CoA-Oxidase (ACOX), and Acyl-CoA Thioesterase (ACOT) Genes in Mutant Fungal Strains

Quantitative reverse transcription polymerase chain reaction (qRT-PCR) analysis was conducted to evaluate the mRNA levels of the TE, ACOX, and ACOT genes in the M-1, M-2, and M-3 recombinant strains. All recombinant strains were first grown in a 5-L fermenter with $\mathrm{K}$ and $\mathrm{R}$ medium and samples were collected at 24,48 , and $72 \mathrm{~h}$ growth intervals. The TE mRNA was maintained at elevated levels, ultimately confirming that the TE gene was truly over-expressed in all mutant strains, (i.e., M-1, M-2, and $\mathrm{M}-3$ ). In the case of other mutant strains (i.e., M-2, M-3), the M-2 strain was further evaluated for the ACOX knockout, while M-3 strain for ACOX and ACOT knockouts (KOs). ACOX and ACOT expression were extremely low, and only an insignificant level of mRNA was detected throughout the cultivation period. These results confirmed that the targeted genes had been deleted in these mutant strains (Figure 6). 


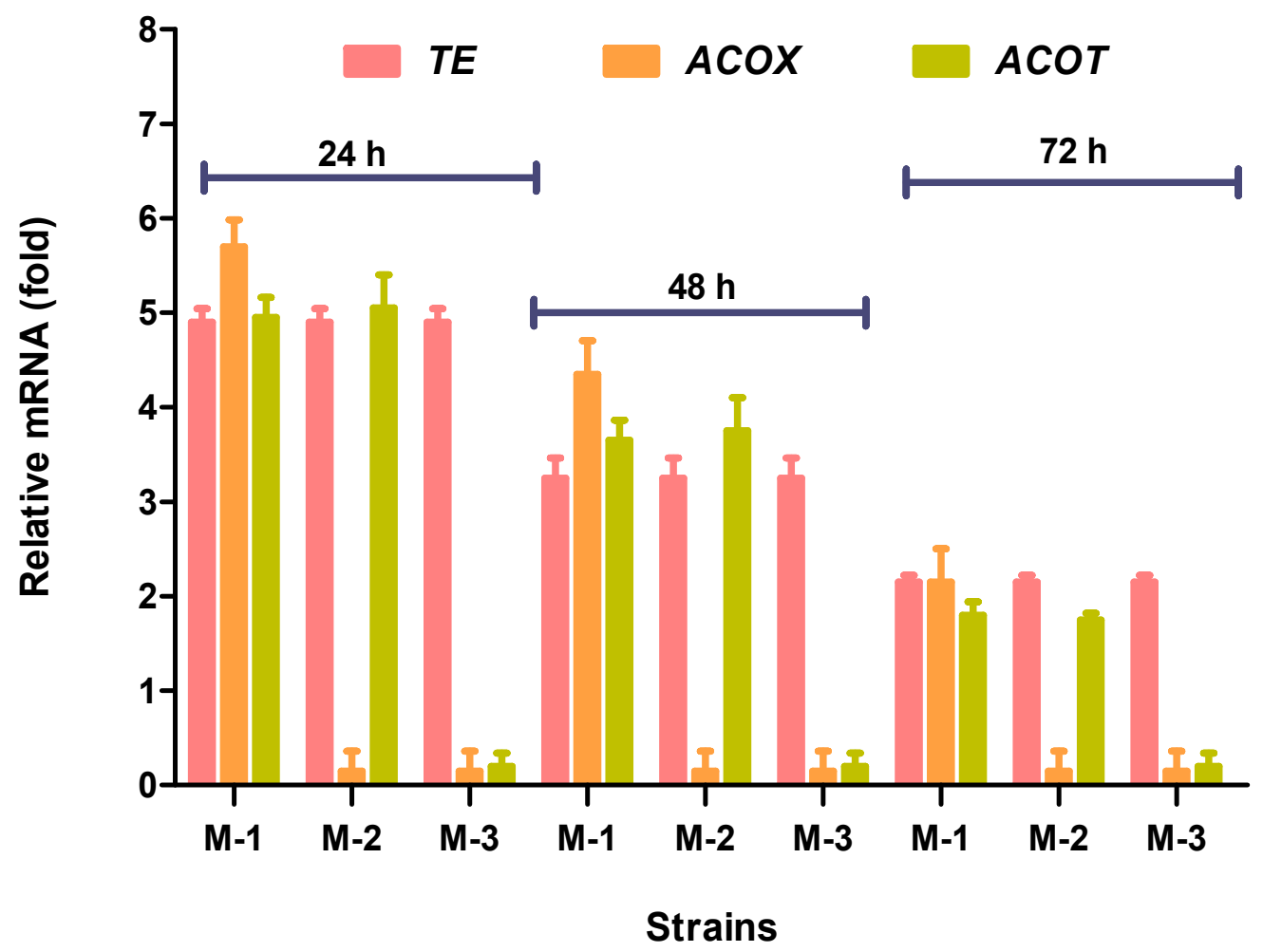

Figure 6. Determination of expression levels of TE, ACOX, and ACOT genes by RT-qPCR in the recombinant strains. Values were the mean of three independent experiments. Error bars represent the standard error of the mean.

\subsection{Fungal Cell Growth and Lipid Yield from Mutant Fungal Strains}

Fungal cell growth, total lipid contents, and specific lipid yields in all mutant strains (i.e., M-1, M-2, and M-3) were evaluated in comparison to the control strain (WT). All strains were grown in a 5-L fermenter for $96 \mathrm{~h}$ in modified $\mathrm{K}$ and R medium (Figure 7A-F). Overall, the growth of all three mutant strains were inhibited (Figure 7A). The CDW of all mutant strains diverged and was lower than the control strain (WT) from the initial cultivation stage $(12 \mathrm{~h})$, ultimately demonstrating the effects of the genetic modulation from the onset of cultivation. Moreover, TE over-expression and consequent disruption of the ACOX and ACOT genes in these mutant strains also demonstrated the profound shift in the growth phases, since the majority of the mutant strains, excluding $\mathrm{M}-3$, had a shorter stationary phase. Consequently, growth declined after $72 \mathrm{~h}$ of cultivation (Figure 7A,B). The compacted growth has been previously attributed to a shift in the metabolic machinery of the cell towards high lipid production (Figure 7A-D). Similarly, in our case, the genetic manipulation significantly impacted lipid accumulation in strain M-1 and, of note, strain M-2. All engineered strains (i.e., M-1, M-2, and M-3) showed total increases in lipid accumulation ranging from $47 \pm 2.4$ to $68 \pm 2.2 \%$, as compared to $36 \pm 2 \%$ in the control strain (WT) (Figure 7C). In addition to the total lipid contents (TLC), the engineered strains, i.e., M-1, M-2, and M-3, biosynthesized $0.54 \pm 0.013$, $0.68 \pm 0.041$, and $0.47 \pm 0.061 \mathrm{~g}$ lipid per gram CDW, respectively. In contrast, the control strain (WT) produced $0.36 \pm 0.29 \mathrm{~g}$ lipid per gram CDW, indicating that the enhanced specific lipid productivity was attributed to the compacted growth of the engineered strains capable of producing non-native fatty acids (Figure 7D). Moreover, the fatty acid portfolio also demonstrated that the genetic manipulation also modified the fatty acid composition in all the mutant strains (Figure 8, Table 2). The nitrogen and glucose consumption rates were comparable among M-1, M-3, and WT, while M-2 strain exhibited comparatively rapid glucose utilization (Figure 7E,F). 
A

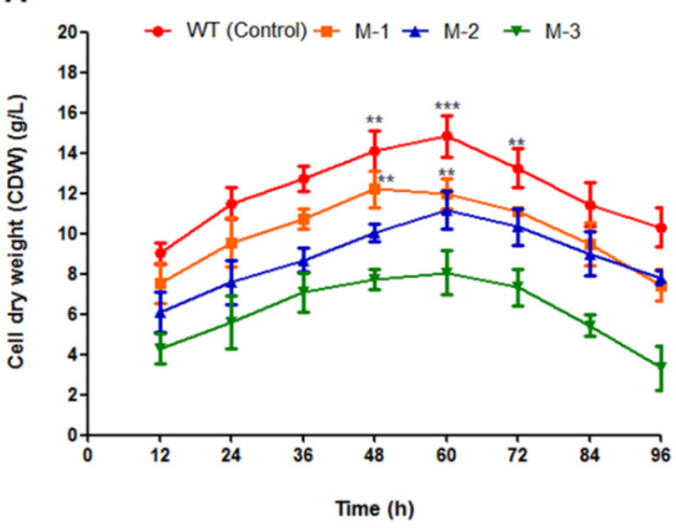

C

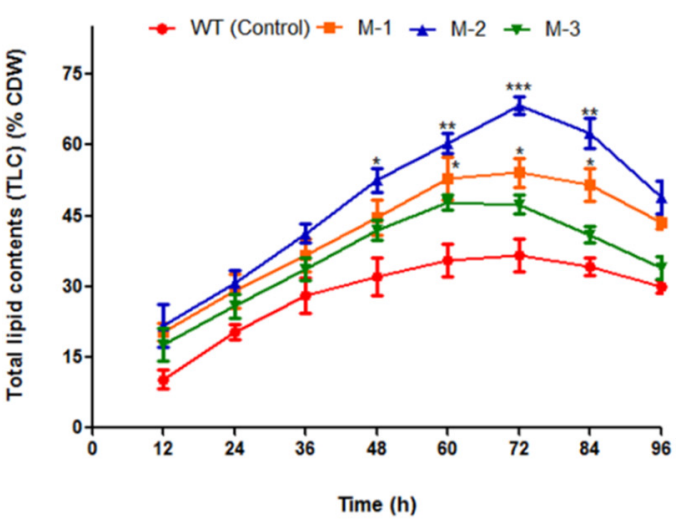

E

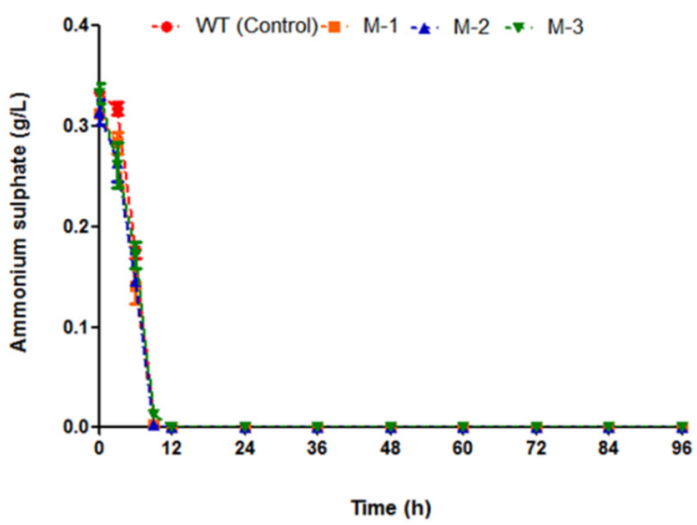

B

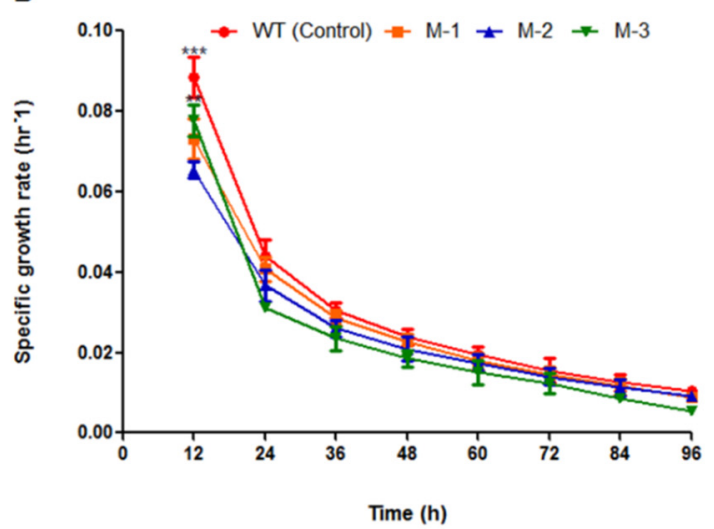

D

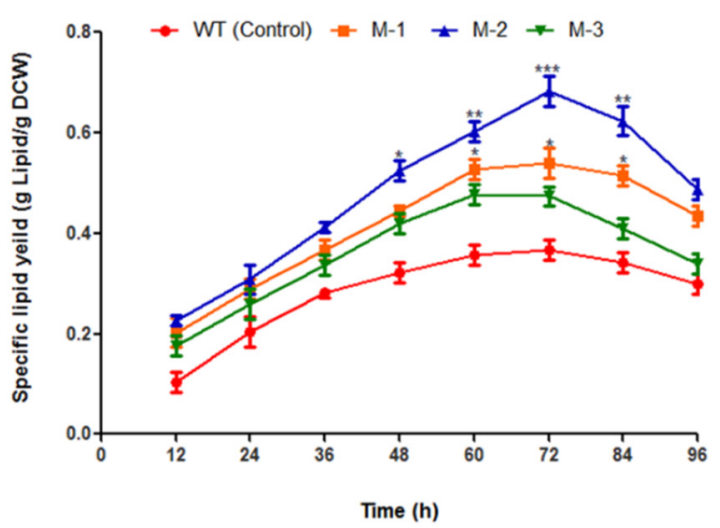

$\mathbf{F}$

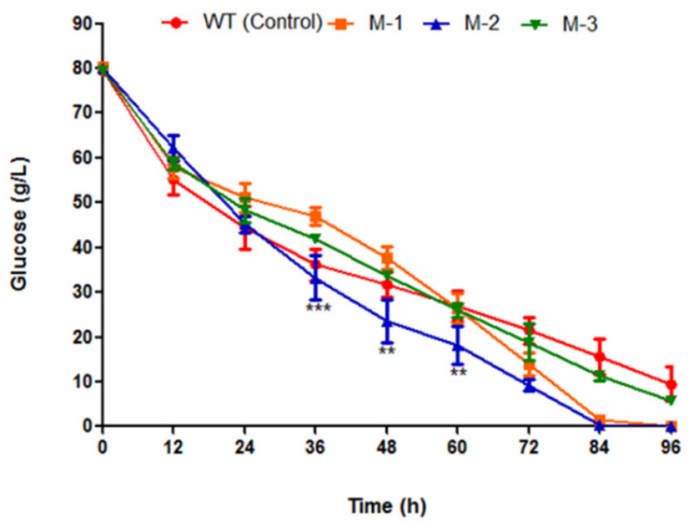

Figure 7. (A-F) Cell growth, lipid accumulation, and substrate consumption of control (WT) and mutant strains (i.e., $\mathrm{M}-1, \mathrm{M}-2$, and $\mathrm{M}-3$ ) cultivated in a 5 - $\mathrm{L}$ fermenter with $1.5 \mathrm{~L}$ modified $\mathrm{K}$ and $\mathrm{R}$ medium for $96 \mathrm{~h}$. (A) Cell dry weight (CWD), (B) specific growth rate, (C) percentage of total lipid content from CDW, (D) specific lipid yield, (E) ammonium sulfate concentration, and (F) residual glucose concentration. Values were the mean of three independent experiments. Error bars represent the standard error of the mean. Asterisks indicate that the differences $\left({ }^{*} p<0.05 ;{ }^{* *} p<0.01 ;{ }^{* * *} p<0.001\right)$ between the means of different treatments are statistically significant. 
A

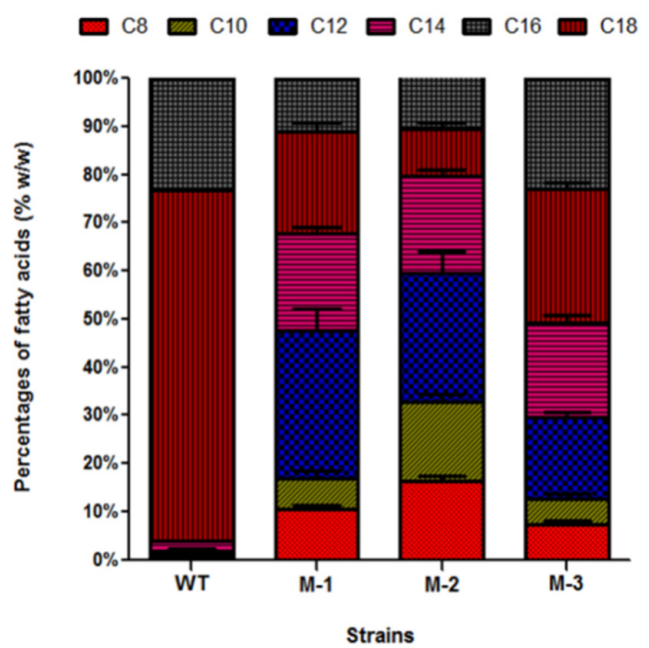

C

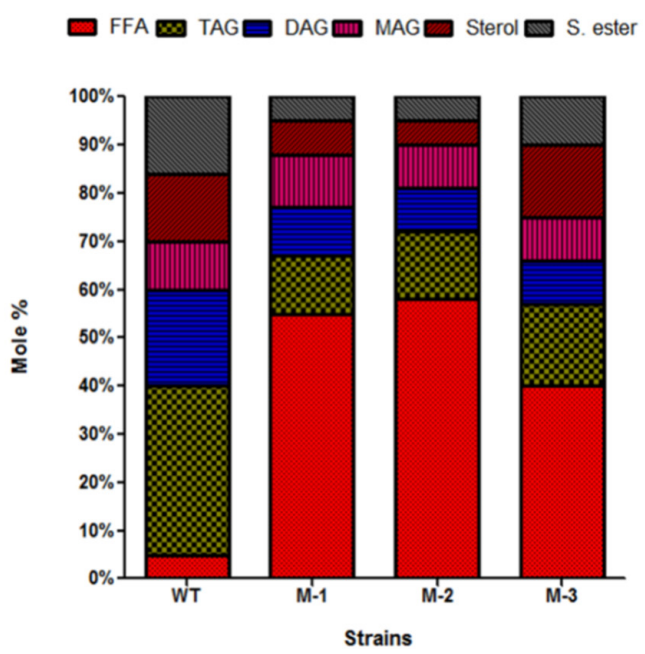

B

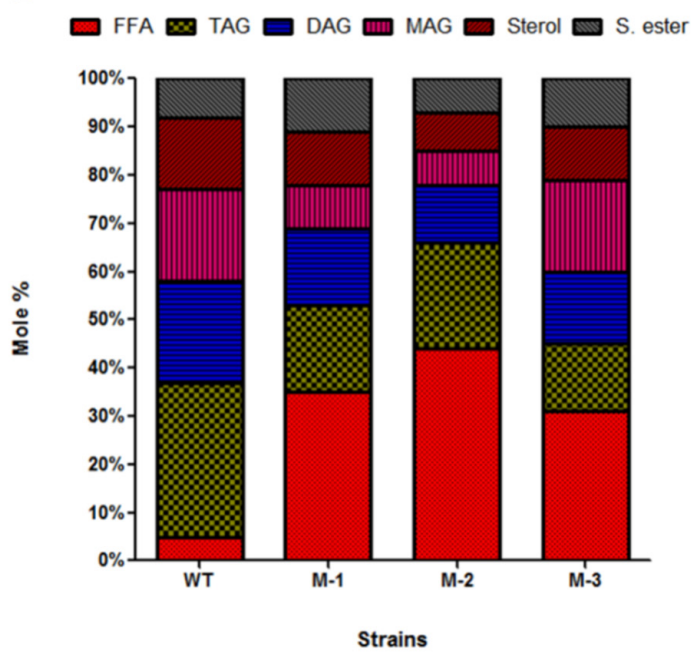

D
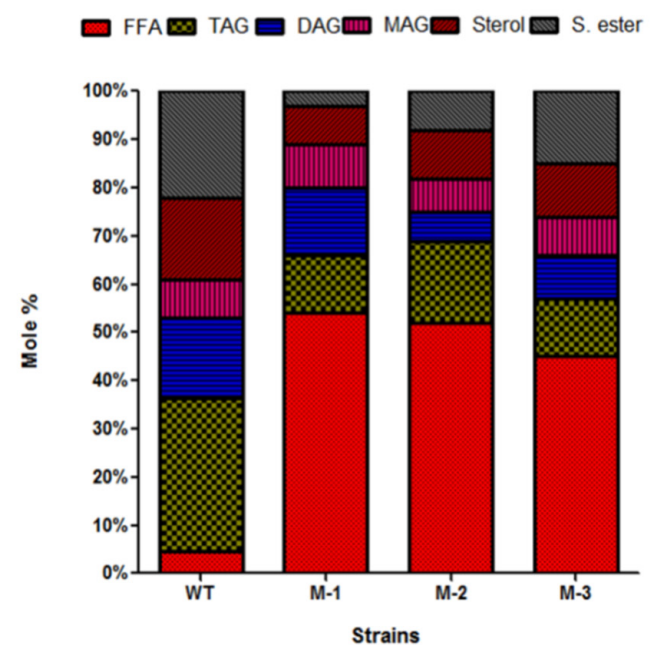

Figure 8. (A) Fatty acid (FA) profiles of the control (WT) and engineered strains, (B) Abundance of medium-chain lipids, (C) 16-carbon lipids, and (D) 18-carbon lipids from engineered strains of M. circinelloides (MU758) in different lipid classes, i.e., free fatty acids (FFA), triacylglycerol (TAG), diacylglycerol (DAG), monoacylglycerol (MAG), sterol, and steryl ester (S. ester).

Table 2. Fatty acid portfolio in control and mutant strains of M. circinelloides MU758.

\begin{tabular}{lcccc}
\hline & WT (Control) & M-1 & M-2 & M-3 \\
\hline CDW (g/L) & $13.28 \pm 1.37^{\mathrm{a}}$ & $11.14 \pm 0.21^{\mathrm{b}}$ & $10.45 \pm 1.26^{\mathrm{b}}$ & $07.35 \pm 1.29$ \\
\%TLC (CDW) & $36.70 \pm 0.21$ & $54.85 \pm 1.20^{\mathrm{b}}$ & $68.85 \pm 2.20^{\mathrm{a}}$ & $47.01 \pm 2.40^{\mathrm{c}}$ \\
TLC (g/L) & $04.87 \pm 0.23$ & $06.11 \pm 0.12^{\mathrm{a}}$ & $07.19 \pm 0.08^{\mathrm{a}}$ & $03.46 \pm 0.09$ \\
\% MCFAs $_{\text {MCFAs (g/L) }}$ & $02.25 \pm 1.10$ & $47.45 \pm 1.80^{\mathrm{b}}$ & $60.09 \pm 2.10^{\mathrm{a}}$ & $29.61 \pm 0.80^{\mathrm{c}}$ \\
P $_{\text {TL }}$ & $0.11 \pm 0.71$ & $02.88 \pm 0.04^{\mathrm{b}}$ & $04.32 \pm 0.09^{\mathrm{a}}$ & $01.04 \pm 0.05$ \\
P $_{\text {MCFAs }}$ & $1217.5 \pm 0.11^{\mathrm{c}}$ & $1527.5 \pm 0.41^{\mathrm{b}}$ & $1800.5 \pm 1.2^{\mathrm{a}}$ & $865.1 \pm 0.25$ \\
\hline
\end{tabular}

Fatty acid composition of the control (WT) and mutant strains (i.e., M-1, M-2, and M-3) of M. circinelloides (MU758). Total lipid (TLC) and MCFAs contents are provided in $\% \mathrm{w} / \mathrm{w}$ of CDW and \% w/w of total lipid (g/L), respectively, for all strains. The MCFAs (C8-C12) contents are also presented in $\mathrm{g} / \mathrm{L}$. Lipid productivity $\left(\mathrm{P}_{\mathrm{TL}}\right)$ and MCFAs productivity ( $\mathrm{P}_{\text {MCFAs }}$ ) were provided in $\mathrm{mg} / \mathrm{L}$.d. CDW, TLC and productivities $\left(\mathrm{P}_{\mathrm{TL}}, \mathrm{P}_{\mathrm{MCFAs}}\right.$ ) were calculated after cultivation of the aforesaid strains over $72 \mathrm{~h}$ in modified $\mathrm{K}$ and $\mathrm{R}$ medium. The values represent the mean \pm SD of three independent experiments. For different strains, with different genetic makeup, means with different letters were significantly different, with alphabetical order of letters ${ }^{\mathrm{a}-\mathrm{c}}$ ) representative of the highest to lowest content. The values without a letter are considered statically non-significant. 
M. circinelloides strains naturally produced LCFAs (i.e., C16-C18). Combined strategy of TE over-expression and the $\beta$-oxidation pathway modification by disrupting the ACOX gene in $\mathrm{M}-2$ strain played a pivotal role in augmenting MCFAs production. The engineered strains, i.e., $\mathrm{M}-1$ and $\mathrm{M}-2$, generated maximum amounts of total lipids at $72 \mathrm{~h}$ of cultivation growth, so we calculated MCFAs abundance at $72 \mathrm{~h}$. Medium chain fatty acids (C8-C12) in the wild type strain were minimum $(2.25 \%)$, in M-1 were $47.45 \pm 1.8 \%$, with the highest being M-2 $(60.09 \pm 2.1 \%)$. While the M-3 strain producedcomparatively less MCFAs than M-1 (i.e., $29.61 \pm 0.8 \%$ ) under the same growth conditions. We also speculated that the incremental trend in MCFAs was correlated with the depletion of C18-containing fatty acids (Figure 8A). Fatty acid portfolio of control and mutant strains of M. circinelloides MU758 are represented at Table 2.

\subsection{Incorporation of De Novo Medium-Chain Fatty Acids (MCFAs) into Diverse Lipid Classes}

To calculate the potential of mutant strains (i.e., M-1, M-2, and M-3) of M. circinelloides MU758 to integrate the de novo MCFAs into different lipid classes, we employed chromatography to fractionate the total lipids into different classes, such as triacylglycerides (TAGs), diacylglycerides (DAGs), monoacylglycerides (MAGs), sterols, and steryl esters, and the level of each fraction was estimated.

We speculate that there is an inverse correlation between the abundance of FFAs and TAGs. The control strain (WT) demonstrated the maximum quantity in the TAG fraction (i.e., 32\%) of the total lipid content (TLC) in comparison to the engineered strains (i.e., $18 \%, 22 \%$, and $14 \%$ for M-1, M-2, and M-3, respectively). However, larger amounts of FFAs were detected in all engineered strains (i.e., $35 \%, 44 \%$, and $31 \%$ for $\mathrm{M}-1, \mathrm{M}-2$, and $\mathrm{M}-3$, respectively) in comparison to the control strain $(1.2 \%)$.

Surprisingly, these non-native MCFAs were found to be integrated into all lipid classes. All fractions of total lipids for the control and engineered strains are depicted (Figure 8B). Our results demonstrated that all engineered strains contained significant quantities of MCFAs in the FFA and TAG fractions (Figure 8B).

In addition to the incorporation of MCFAs into the diverse classes of lipids, TE gene over-expression and sequential disruptions of $A C O X$ and $A C O T$ genes also influenced the localization of native fatty acids. In the context of $\mathrm{C} 16$ fatty acids, the mutant strains demonstrated elevated production of FFAs (i.e., $55 \%, 58 \%$, and $40 \%$ of FFAs for M-1, M-2, and M-3, respectively) compared with $4.2 \%$ of FFAs in the control (Figure 8C). Concerning C18 fatty acid production, an incremental pattern of FFAs was also noticed in all mutant strains in comparison to the control strain (Figure 8D).

\section{Discussion}

\subsection{The Impact of Heterologous Thioesterase (TE) Protein Over-Expression on Total Lipids and Fatty Acid Composition in the Mutant Fungal Strains}

On a global scale, due to their natural ability to produce lipids in significant amounts, oleaginous microorganisms (i.e., Bacteria/yeast/fungi) are regarded as potential sources of different industrial commodities. Previously, several studies have described the potential of $M$. circinelloides to generate diverse compounds of biotechnological interest $[9,14,15,63,64]$. Like Y. lipolytica and other oleaginous microbes [20,37], M. circinelloides also produces LCFAs (i.e., C16-C18) in significant abundance. In addition, this fungus has no natural tendency to produce MCFAs due to the absence of MCFAs-producing pathways. In contrast, there is an increasing demand for MCFAs production as a substrate for the functional food and jet-fuel industries due to their unique physiochemical properties $[6,18,35-43]$. To achieve this goal, we first over-expressed the TE protein from $U$. californica in M. circinelloides strain MU758 to overproduce MCFAs. The resultant mutant (i.e., M-1) demonstrated a 1.42-1.63-fold increase in lipid production. One possible reason for the rise in total lipid accumulation in the aforesaid engineered strain can be attributed to particular function of TE protein in reducing the numerous feedback inhibition reactions (i.e., removing the inhibition of acyl-ACPs etc.) and consequentially, driving the elevated flux towards lipid production [37,65-67]. 
Interestingly, MCFAs production also increased up to $47.48 \%$, with $10.41 \%$ and $6.35 \%$ increase for C8 and C10 fatty acids respectively, and 30.73\% for C12. Concomitantly, the abundance of long chain fatty acids, (i.e., C16 and C18) declined from 0.28-fold to 0.47-fold. Heterologous TE protein localizes in the reaction center of fungal FASs to facilitate the access of acyl-ACP/acyl-CoA substrates to their catalytic sites. We observed that the increasing turnover of MCFAs to contribute the fatty acids abundance was directly correlated with the decline in the abundance of C16-containing and C18-containing lipids.This is possibly due to reason that acyl-ACP thioesterases having substrate specificities for medium-chain acyl-ACPs were incorporated into the native fungal FAS system and assisted the earlier discontinuation of fatty acid elongation to ultimately produce more quantities of MCFAs. This approach has been shown to serve as a potential tool to increase the carbon flux towards the fatty acid biosynthetic pathway (i.e., FASs) to achieve a significant abundance of MCFAs in M. circinelloides. Previous reports on E. coli and Y. lipolytica have described the low turnover of C8 and C10-containing lipids from the tested TE proteins [5,19,20,32,68-70].

Biologically, fatty acids are found in different classes of lipids, such as FFAs, sterols, steryl esters, TAGs, DAGs, and MAGs. This distribution allows the involvement of various enzymes with specific activity towards non-native fatty acids. Similar to our previous investigation, we noticed the presence of de novo fatty acids in all the aforesaid lipid fractions; therefore, characterization of the biosynthetic machinery (i.e., FASs) of M. circinelloides MU758 has the potential to allow the recognition and amendment of fatty acids as short as octanoic acid (i.e., C8). All mutant strains (i.e., M-1, M-2, and M-3) showed different quantities of various lipid classes. Generally, an antagonistic correlation was observed among TAGs, sterols, and FFAs proportions. Moreover, the quantity of FFAs increased in all mutant strains, with a corresponding reduction in the TAG and sterol proportions. Conversely, in the perspective of MCFAs, a similar trend was not observed, excluding a change in LCFAs length. The increased quantity of de novo MCFAs was associated with elevations in FFA abundance in all mutant strains.

4.2. Combined Impact of TEOver-Expression and ACOX (and ACOT) Gene Disruption on Lipid Accumulation and the Fatty Acid Portfolio in the Mutant Fungal Strains

For initial gene disruption step, we modified the $\beta$-oxidation pathway with the intention of further enhancing the MCFAs quantity. To achieve this goal, we first disrupted the peroxisomal ACOX gene responsible for the oxidation of MCFAs. We observed significant increase in total lipid accumulation in strain M-2 with lipid productivity of $\sim 1800 \mathrm{mg} / \mathrm{L} . \mathrm{d}$ and MCFAs productivity $\sim 1100 \mathrm{mg} / \mathrm{L} . \mathrm{d}$, while the growth rate was negatively affected in this strain. Moreover, noteworthy increases (i.e., 26.63\%) in the percentages of C8, C10, and C12-containing fatty acids were also observed in comparison to the M-1 strain. Peroxisomes of the engineered fungal strain from the current investigation (i.e., M-2) were genetically manipulated in such a controlled manner to degrade only long-chain fatty acids [24] and possible overproduction of medium-chain acyl-CoAs and acetyl-CoA. This aforesaid event indicating that degradation of LCFA can be an additional way of increasing MCFA different from that previously proposed [71]. The degraded acetyl-CoA product was converted into the active form called acetyl carnitine and then transported out of peroxisomes through carnitine acetyl-transferase shuttle system [58].In addition, transferase enzyme activity was present in M. circinelloides $[4,7,19,20]$, which possibly facilitates the transportation of medium-chain acyl-CoAs and recycling of CoASH. Our results are consistent with a previous study of $S$. cerevisiae showing that genetic manipulation of peroxisomal ACOX genes led to increments in TLC and MCFAs production in the mutant strains [24]. Subsequent disruption of the specific ACOT gene in the M-3 strain drove stunted fungal growth with comparatively less lipid accumulation as well as reduced MCFAs (i.e., 37.59) and FFA production in comparison to M-1 strain. The M-3 strain eventually validated the involvement of the ACOT gene in the production of FFA and facilitated the transportation of MCFAs out of peroxisomes by specific membrane transporters [57]. Based on our above discussion, we assumed that the disruption of specific $A C O X$ protein and presence of the ACOT gene in peroxisomes may facilitate the abundance of cytosolic 
medium-chain acyl-CoAs in the mutant strain (i.e., M-2), ultimately enhancing the production of FFAs and MCFAs. However, future studies are needed to estimate the concentration of medium-chain acyl-CoAs [24,72].

Furthermore, prior studies have also elaborated a modification in the $\beta$-oxidation pathway that switches the virulence potential of various fungal strains to a minimal level [55,73-76], but extensive investigations are needed to verify the outcome in this respect. Taken together, the current synergistic approach provided an innovative tool for MCFAs over-production in $M$. circinelloides strain MU758. However, outcomes related to the modification of the $\beta$-oxidation pathway demonstrated a persistent need for further investigations to oxidize more LCFAs and ultimately produce increased amounts of MCFAs. Our future investigations will focus on the genetic manipulation of $\beta$-oxidation pathway-related genes, such as other ACOXs and ACOTs, thiolase acetyl-synthetase [7,18,57], as well as the over-expression of diverse genes encoding lipase, acetyl-CoA carboxylase (ACC), and malic enzyme (ME), eventually to enhance the total fatty acid and, exclusively, the MCFAs contents [77-80].

\section{Conclusions}

In our current investigations, all mutant strains showed elevated production of total lipids (i.e., 1.25-1.47-fold) and MCFAs (i.e., 13-26-fold), especially the mutant strain M-2. Mutant strain M-2 due to synergistic effect of TE over-expression and $\beta$-oxidation pathway modification significantly augmented the MCFAs production. Finally, we also noticed the incorporation of MCFAs in all various classes of lipids. Hence, we concluded that M. circinelloides strain MU758 can be engineered to overproduce MCFAs with improved metabolic-flux through the FASs and $\beta$-oxidation pathways. The combined strategy of over-expressing TE protein and modifying the $\beta$-oxidation pathway provides a novel opportunity to produce diverse compounds of biotechnological interest.

Supplementary Materials: The following are available online at http://www.mdpi.com/2073-4425/11/8/890/s1, Tables S1-S3. Primer used for this study. Figure S1. PCR amplification of genome of control (WT), and mutant strain (M-1). Figure S2. Confirmation of disruption of ACOX gene in M-1 mutant strain.

Author Contributions: S.A.H. and A.G. carried out the experiments. S.A.H. drafted the manuscript. M.A.K.K., S.N. and Y.Z. assisted in GC analysis. V.G., S.C.L., and Y.S. participated in the experimental design and reviewed the manuscript. M.A.G.K. reviewed the final manuscript and helped in discussion. Y.S. conceived the study and reviewed the final manuscript. All authors read and approved the final manuscript.

Funding: This work was supported by the National Natural Science Foundation of China $(31670064,31972851)$, the TaiShan Industrial Experts Program (tscy 20160101), the Chinese Government Scholarship Council (CSC) to Y.S., and the National Institutes of Health/National Institute of Allergy and Infectious Diseases (NIH/NIAID) Grant R03 AI11917 and the University of Texas at San Antonio research funds to S.C.L.

Acknowledgments: We are indebted to Wu Yang and Young Huh for technical assistance, to Scarlett Geunes-Boyer, Yusuf Nazir, and Samee Ullah for critical reading and discussions; to Hafiy halim for assisted in graphical work; and to Victoriano Garre and Soo Chan Lee for providing the plasmids and strains used in the present investigation.

Conflicts of Interest: The authors declare no conflict of interest.

$\begin{array}{ll}\text { Abbreviations } \\ \text { MCFAs } & \text { medium-chain fatty acids } \\ \text { LCFAs } & \text { long chain fatty acids } \\ \text { TE } & \text { Thioesterase } \\ \text { CDW } & \text { cell dry weight } \\ \text { M.C } & \text { Mucor circinelloides } \\ \text { FFA } & \text { free fatty acid } \\ \text { HR } & \text { homologous recombination } \\ \text { TLC } & \text { total lipid contents } \\ \text { ACP } & \text { acyl-carrier protein } \\ \text { FAME } & \text { fatty acid methyl esters } \\ \text { ACOX } & \text { acyl-CoA oxidase }\end{array}$




$\begin{array}{ll}\text { ACOT } & \text { acyl-CoA thioesterase } \\ \text { FAS } & \text { fatty acid synthase } \\ \text { Vvm } & \text { volume of air per volume of medium per min } \\ \text { TAG } & \text { Triacylglycerol } \\ \text { DAG } & \text { Diacylglycerol } \\ \text { MAG } & \text { Monoacylglycerol } \\ \text { SE } & \text { steryl ester } \\ \text { MMC } & \text { minimal media with casamino acids } \\ \text { YPG } & \text { yeast peptone glucose } \\ \text { GC } & \text { gas chromatography }\end{array}$

\section{References}

1. Fortman, J.; Chhabra, S.; Mukhopadhyay, A.; Chou, H.; Lee, T.S.; Steen, E.; Keasling, J.D. Biofuel alternatives to ethanol: Pumping the microbial well. Trend Biotechnol. 2008, 26, 375-381. [CrossRef]

2. Allouche, Y.; Cameleyre, X.; Guillouet, S.; Hulin, S.; Thevenieau, F.; Akomia, L.; Molina-Jouve, C. ProBio3 Project: How to Achieve Scientific and Technological Challenges to Boost the Sustainable Microbial Production of Lipids as Biojet Fuel and Chemical CompoundsOCL: Oilseeds Fats Crop. Lipid. 2013, 20, 6D605. [CrossRef]

3. Runguphan, W.; Keasling, J.D. Metabolic engineering of Saccharomyces cerevisiae for production of fatty acid-derived biofuels and chemicals. Metab. Eng. 2014, 21, 103-113. [CrossRef]

4. Hussain, S.A.; Hameed, A.; Khan, M.A.K.; Zhang, Y.; Zhang, H.; Garre, V.; Song, Y. Engineering of Fatty Acid Synthases (FASs) to Boost the Production of Medium-Chain Fatty Acids (MCFAs) in Mucor circinelloides. Int. J. Mol. Sci. 2019, 20, 786. [CrossRef]

5. Xu, P.; Qiao, K.; Ahn, W.S.; Stephanopoulos, G. Engineering Yarrowia lipolytica as a Platform for Synthesis of Drop-in Transportation Fuels and Oleochemicals. Proc. Natl. Acad. Sci. USA 2016, 113, 10848-10853. [CrossRef]

6. Xu, P.; Li, L.; Zhang, F.; Stephanopoulos, G.; Koffas, M. Improving fatty acids production by engineering dynamic pathway regulation and metabolic control. Proc. Natl. Acad. Sci. USA 2014, 111, 11299-11304. [CrossRef]

7. Tang, X.; Zhao, L.; Chen, H.; Chen, Y.Q.; Chen, W.; Song, Y.; Ratledge, C. Complete Genome Sequence of a High Lipid-Producing Strain of Mucor circinelloides WJ11 and Comparative Genome Analysis with a Low Lipid-Producing Strain CBS 277.49. PLoS ONE 2015, 10, e0137543. [CrossRef]

8. Naz, T.; Nosheen, S.; Li, S.; Nazir, Y.; Mustafa, K.; Liu, Q.; Garre, V.; Song, Y. Comparative Analysis of $\beta$-Carotene Production by Mucor circinelloides Strains CBS 277.49 and WJ11 under Light and Dark Conditions. Metabolites 2020, 10, 38. [CrossRef]

9. Zhang, Y.; Luan, X.; Zhang, H.; Garre, V.; Song, Y.; Ratledge, C. Improved $\gamma$-linolenic acid production in Mucor circinelloides by homologous overexpressing of delta-12 and delta-6 desaturases. Microb. Cell Fact. 2017, 16, 113. [CrossRef]

10. Sakuradani, E.; Kobayashi, M.; Shimizu, S. Delta6-fatty acid desaturase from an arachidonic acid-producing Mortierella fungus. Gene cloning and its heterologous expression in a fungus, Aspergillus. Gene 1999, 238, 445-453. [CrossRef]

11. Kelder, B.; Mukeji, P.; Kirchner, S.; Hovanec, G.; Leonard, A.E.; Chuang, L.T.; Kopchick, J.J.; Huang, Y.S. Expression of fungal desaturase genes in cultured mammalian cells. Mol. Cell Biochem. 2001, 219, 7-11. [CrossRef]

12. Michinak, Y.; Aki, T.; Shimauchi, T.; Nakajima, T.; Kawamoto, S.; Shigeta, S.; Suzuki, O.; Ono, K. Differential response to low temperature of two Delta6 fatty acid desaturases from Mucor circinelloides. Appl. Microbiol. Biotechnol. 2003, 62, 362-368. [CrossRef]

13. Tang, X.; Zhang, H.; Chen, H.; Chen, Y.Q.; Song, Y. Effects of 20 standard amino acids on the growth, total fatty acids production, and gamma-linolenic acid yield in Mucor circinelloides. Curr. Microbiol. 2014, 69, 899-908. [CrossRef]

14. Carvalho, A.K.F.; Rivaldi, J.D.; Barbosa, J.C.; Castro, H.F.D. Biosynthesis, characterization and enzymatic transesterification of single cell oil of Mucor circinelloides-A sustainable pathway for biofuel production. Bioresour. Technol. 2015, 181, 47-53. [CrossRef] 
15. Carvalho, A.K.F.; Conceicao, L.R.V.D.; Silva, J.P.V.; Perez, V.H.; Castro, H.F.D. Biodiesel production from Mucor circinelloides using ethanol and heteropolyacid in one and two-step transesterification. Fuel 2017, 202, 503-511. [CrossRef]

16. Khan, M.A.K.; Yang, J.; Hussain, S.A.; Zhang, H.; Garre, V.; Song, Y. Genetic modification of Mucor circinelloides to construct stearidonic acid producing cell factory. Int. J. Mol. Sci. 2019, 20, 1683. [CrossRef]

17. Khan, M.A.K.; Yang, J.; Hussain, S.A.; Zhang, H.; Garre, V.; Song, Y. Construction of DGLA producing cell factory by genetic modification of Mucor circinelloides. Microb. Cell Fact. 2019, 18, 64. [CrossRef]

18. Sarria, S.; Kruyer, N.S.; Yahya, P.P. Microbial synthesis of medium-chain chemicals from renewable. Nat. Biotechnol. 2017, 35, 1158-1166. [CrossRef]

19. Rigouin, C.; Gueroult, M.; Croux, C.; Dubosis, G.; Borsenberger, V.; Barbe, S.; Marty, A.; Daboussi, F.; André, I.; Bordes, F. Production of Medium Chain Fatty Acids by Yarrowia lipolytica: Combining Molecular Design and TALEN to Engineer the Fatty Acid Synthase. ACS Synth. Biol. 2017, 6, 1870-1879. [CrossRef]

20. Ruter, C.D.; Zhang, S.; Rao, C.V. Engineering Yarrowia lipolytica for production of medium-chain fatty acids. Appl. Microbiol. Biotechnol. 2015, 99, 7359-7368. [CrossRef]

21. Camões, F.; Islinger, M.; Guimarães, S.C.; Kilaru, S.; Schuster, M.; Godinho, L.F.; Steinberg, G.; Schrader, M. New insights into the peroxisomal protein inventory: Acyl-CoA oxidases and dehydrogenases are an ancient feature of peroxisomes. Biochim. Biophy. ActaMol. Cell Res. 2015, 1853, 111-125. [CrossRef] [PubMed]

22. Lodhi, I.J.; Semenkovich, C.F. Peroxisomes: A nexus for lipid metabolism and cellular signaling. Cell Metab. 2014, 19, 380-392. [CrossRef]

23. Gabriel, F.; Accoceberry, I.; Bessoule, J.J.; Salin, B.; Lucas-Guérin, M.; Manon, S.; Dementhon, K.; Noël, T. A Fox2-Dependent Fatty Acid $\beta$-Oxidation Pathway Coexists both in Peroxisomes and Mitochondria of the Ascomycete Yeast Candida lusitaniae. PLoS ONE 2014, 9, e114531. [CrossRef] [PubMed]

24. Chen, L.; Zhang, J.; Chen, W.N. Engineering the Saccharomyces cerevisiae $\beta$-Oxidation Pathway to Increase Medium Chain Fatty Acid Production as Potential Biofuel. PLoS ONE 2014, 9, e84853. [CrossRef]

25. Zhou, Y.J.; Buijs, N.A.; Zhu, Z.; Qin, J.; Siewers, V.; Nielsen, J. Production of fatty acid-derived oleochemicals and biofuels by synthetic yeast cell factories. Nat. Commun. 2016, 7, 11709. [CrossRef] [PubMed]

26. Lian, J.; Zhao, H. Reversal of the $\beta$-oxidation cycle in Saccharomyces cerevisiae for production of fuels and chemicals. ACS Synth. Biol. 2015, 4, 332-341. [CrossRef] [PubMed]

27. Kim, S.; Clomburg, J.M.; Gonzalez, R. Synthesis of medium-chain length (C6-C10) fuels and chemicals via $\beta$-oxidation reversal in Escherichia coli. J. Ind. Microbiol. Biotechnol. 2015, 42, 465-475. [CrossRef]

28. Goh, E.B.; Baidoo, E.E.K.; Keasling, J.D.; Beller, H.R. Engineering of bacterial methyl ketone synthesis for biofuels. Appl. Environ. Microbiol. 2012, 78, 70-80. [CrossRef]

29. Dellomonaco, C.; Clomburg, J.M.; Miller, E.N.; Gonzalez, R. Engineered reversal of the $\beta$-oxidation cycle for the synthesis of fuels and chemicals. Nature 2011, 476, 355-359. [CrossRef]

30. Cronan, J.E.; Rock, C.O. Biosynthesis of Membrane Lipids Escherichia coli and Salmonella: Cellular and Molecular Biology, 2nd ed.; ASM Press: Washington, DC, USA, 1996; pp. 612-636.

31. Harwood, J.L. Fatty acid metabolism. Ann. Rev. Plant Physiol. Plant Mol. Biol. 1988, 39, 101-138. [CrossRef]

32. Zhu, Z.; Zhou, Y.J.; Krivoruchko, A.; Grininger, M.; Zhao, Z.K.; Nielsen, J. Expanding the product portfolio of fungal type I fatty acid synthases. Nat. Chem. Biol. 2017, 13, 360-362. [CrossRef] [PubMed]

33. Gajewski, J.; Pavlovic, R.; Fischer, M.; Boles, E.; Grininger, M. Engineering fungal de novo fatty acid synthesis for short chain fatty acid production. Nat. Commun. 2017, 8, 14650. [CrossRef] [PubMed]

34. Liu, X.; Hicks, W.M.; Silver, P.A.; Way, J.C. Engineering acyl carrier protein to enhance production of shortened fatty acids. Biotechnol. Biofuel. 2016, 9, 24. [CrossRef] [PubMed]

35. Cabrales, L.; Calderon, K.; Hinojosa, I.; Valencia, F.; Abidi, N. Synthesis and characterization of polyesters derived from sebacic acid, hexanediol, and hydroquinone. Int. J. Polym. Anal. Charact. 2016, 21, 718-727. [CrossRef]

36. Leber, C.; Da-Silva, N.A. Engineering of Saccharomyces cerevisiae for the synthesis of short chain fatty acids. Biotechnol. Bioeng. 2014, 111, 347-358. [CrossRef]

37. McMahon, M.D.; Prather, K.L. Functional screening and in vitro analysis reveal thioesterases with enhanced substrate specificity profiles that improve short-chain fatty acid production in Escherichia coli. Appl. Environ. Microbiol. 2014, 80, 1042-1050. [CrossRef]

38. Torella, J.P.; Ford, T.J.; Kim, S.N.; Chen, A.M.; Way, J.C.; Silver, P.A. Tailored fatty acid synthesis via dynamic control of fatty acid elongation. Proc. Natl. Acad. Sci. USA 2013, 110, 11290-11295. [CrossRef] 
39. Choi, Y.J.; Lee, S.Y. Microbial production of short-chain alkanes. Nature 2013, 502, 571-574. [CrossRef]

40. Honda-Malca, S.; Scheps, D.; Kühnel, L.; Venegas-Venegas, E.; Seifert, A.; Nestl, B.M.; Hauer, B. Bacterial CYP153A monooxygenases for the synthesis of omega-hydroxylated fatty acids. Chem. Commun. 2012, 48, 5115-5117. [CrossRef]

41. Nagao, K.; Yanagita, T. Medium-chain fatty acids: Functional lipids for the prevention and treatment of the metabolic syndrome. Pharm. Res. 2010, 61, 208-212. [CrossRef]

42. Saerens, S.M.G.; Verstrepen, K.J.; Dijck, P.V.; Thevelein, J.M.; Delvaux, F.R. Parameters affecting ethyl ester production by Saccharomyces cerevisiae during fermentation. Appl. Environ. Microbiol. 2008, 74, 454-461. [CrossRef] [PubMed]

43. Knothe, G. "Designer" biodiesel: Optimizing fatty ester composition to improve fuel properties. Energy Fuels 2008, 22, 1358-1364. [CrossRef]

44. Lynd, L.R.; Zyl, V.W.H.; McBride, J.E.; Laser, M. Consolidated bioprocessing of cellulosic biomass: An update. Curr. Opin. Biotech. 2005, 16, 577-583. [CrossRef] [PubMed]

45. Lee, S.C.; Li, A.; Calo, S.; Heitman, J. Calcineur in plays key roles in the dimorphic transition and virulence of the human pathogenic zygomycete Mucor circinelloides. PLoS Pathog. 2013, 9, e1003625.

46. Torres-Martinez, S.; Ruiz-Vázquez, R.M.; Garre, V.; López-García, S.; Navarro, E.; Vila, A. Molecular tools for carotenogenesis analysis in the zygomycete Mucor circinelloides. Method. Mol. Biol. 2012, 898, 85-107.

47. Nicolas, F.E.; de-Haro, J.P.; Torres-Martínez, S.; Ruiz-Vázquez, R.M. Mutants defective in a Mucor circinelloides dicer-like gene are not compromised in siRNA silencing but display developmental defects. Fungal Genet. Biol. 2007, 44, 504-516. [CrossRef]

48. Bartnicki-García, S.; Nickerson, W.J. Nutrition, growth and morphogenesis of Mucor rouxii. J. Bacteriol. 1962, 84, 841-858. [CrossRef]

49. Garcia, A.; Adedoyin, G.; Heitman, J.; Lee, S.C. Construction of a Recyclable Genetic Marker and Serial Gene Deletions in the Human Pathogenic Mucorales Mucor circinelloides. G3 Genes Genomes Genet. 2017, 7, 2047-2054.

50. Hameed, A.; Hussain, S.A.; Yang, J.; Ijaz, M.U.; Liu, Q.; Suleria, H.A.R.; Song, Y. Antioxidants Potential of the Filamentous Fungi (Mucor circinelloides). Nutrients 2017, 9, 1101. [CrossRef]

51. Hussain, S.A.; Nazir, Y.; Hameed, A.; Yang, W.; Mustafa, K.; Song, Y. Optimization of Diverse Carbon Sources and Cultivation Conditions for Enhanced Growthand Lipid and Medium-Chain Fatty Acid (MCFAs) Production by Mucor circinelloides. Fermentation 2019, 5, 35. [CrossRef]

52. Hameed, A.; Hussain, S.A.; Nosheen, S.; Muhammad, Z.; Wu, Y.; Ullah, S.; Suleria, H.A.R.; Song, Y. Microencapsulation of microbial antioxidants from Mucor circinelloides, their physico-chemical characterization, in vitro digestion and releasing behaviors in food. Appl. Biol. Chem. 2020, 63, 28. [CrossRef]

53. Hameed, A.; Hussain, S.A.; Ijaz, M.U.; Ullah, S.; Muhammad, Z.; Suleria, H.A.R.; Song, Y. Antioxidant activity of polyphenolic extracts of filamentous fungus Mucor circinelloides (WJ11): Extraction, characterization and storage stability of food emulsions. Food Bioscience 2020, 34, 100525. [CrossRef]

54. Vellanki, S.; Navarro-Mendoza, M.I.; Garcia, A.; Murcia, L.; Perez-Arques, C.; Garre, V.; Nicolas, F.E.; Lee, S.C. Mucor circinelloides: Growth, maintenance, and genetic manipulation. Curr. Prot. Micro. 2018, 49 , e53. [CrossRef] [PubMed]

55. Kretschmer, M.; Wang, J.; Kronstad, J.W. Peroxisomal and Mitochondrial $\beta$-Oxidation Pathways Influence the Virulence of the Pathogenic Fungus Cryptococcus neoformans. Eukar. Cell. 2012, 11, 1042-1054. [CrossRef]

56. Froman, B.E.; Edwards, P.C.; Bursch, A.G.; Dehesh, K. ACX3, a novel medium-chain acyl-coenzyme A oxidase from Arabidopsis. Plant Physiol. 2000, 123, 733-742. [CrossRef]

57. Hunt, M.C.; Alexson, S.E. Novel functions of acyl-CoA thioesterases and acyltransferases as auxiliary enzymes in peroxisomal lipid metabolism. Prog. Lipid Res. 2008, 47, 405-421. [CrossRef]

58. Hiltunen, J.K.; Mursula, A.M.; Rottensteiner, H.; Wierenga, R.K.; Kastaniotis, A.J.; Gurvitz, A. The biochemistry of peroxisomal beta-oxidation in the yeast Saccharomyces cerevisiae. FEMS Microbiol. Rev. 2003, 27, 35-64. [CrossRef]

59. Folch, J.; Lees, M.; Stanley, G.H.S. A simple method for the isolation and purification of total lipids from animal tissues. J. Biol. Chem. 1956, 226, 497-509.

60. Chaney, A.L.; Marbach, E.P. Modified reagents for determination of urea and ammonia. Clin. Chem. 1962, 8, 130-132. [CrossRef]

61. Carroll, K.K. Separation of lipid classes by chromatography on Florisil. J. Lipid Res. 1961, 2, 135-141. 
62. Freeman, C.; West, D. Complete separation of lipid classes on a single thin-layer plate. J. Lipid Res. 1966, 7 , 324-327. [PubMed]

63. Salunke, D.; Mangalekar, R.; Kuvalekar, A.; Harsulkar, A. Bioconversion of alpha-linolenic acid into long chain polyunsaturated fatty acids by oleaginous fungi. Int. J. Phar. Biol. Sci. 2014, 5, 27-35.

64. Wynn, J.P.; Hamid, A.A.; Li, Y.; Ratledge, C. Biochemical events leading to diversion of carbon into storage lipids in oleaginous fungi Mucor circinelloides and Mortierella alpina. Microbiology 2001, 147, 2857-2864. [CrossRef] [PubMed]

65. Jing, F.; Zhao, L.; Nelson, M.D.Y.; Nikolau, B.J. Two distinct domains contribute to the substrate acyl chain length selectivity of plant acyl-ACP thioesterase. Nat. Commun. 2018, 9, 860. [CrossRef]

66. Ohlrogge, J.B.; Jaworski, J.G. Regulation of fatty acid synthesis. Ann. Rev. Plant Biol. 1997, 48, $109-136$. [CrossRef] [PubMed]

67. Jiang, P.; Cronan, J. Inhibition of fatty acid synthesis in Escherichia coli in the absence of phospholipid synthesis and release of inhibition by thioesterase action. J. Bacteriol. 1994, 176, 2814-2821. [CrossRef]

68. Sherkhanov, S.; Korman, T.P.; Bowie, J.U. Improving the tolerance of Escherichia coli to medium-chain fatty acid production. Metab. Eng. 2014, 25, 1-7. [CrossRef]

69. Hunt, M.C.; Alexson, S.E. The role Acyl-CoA thioesterases play in mediating intracellular lipid metabolism. Prog. Lipid Res. 2002, 41, 99-130. [CrossRef]

70. Stefan, A.; Hochkoeppler, A.; Ugolini, L.; Lazzeri, L.; Conte, E. The Expression of the Cuphea Palustris Thioesterase CpFatB2 in Yarrowia Lipolytica Triggers Oleic Acid Accumulation. Biotechnol. Prog. 2016, 32, 26-35. [CrossRef]

71. Bardi, L.; Cocito, C.; Marzona, M. Saccharomyces cerevisiae cell fatty acid composition and release during fermentation without aeration and in absence of exogenous lipids. Int. J. Food Microbiol. 1999, 47, 133-140. [CrossRef]

72. Kopka, J.; Ohlrogge, J.B.; Jaworski, J.G. Analysis of in Vivo Levels of Acyl- Thioesters with Gas Chromatography/Mass Spectrometry of the Butylamide Derivative. Anal. Biochem. 1995, 224, 251-260. [CrossRef] [PubMed]

73. Casadevall, A. Amoeba provides insight into the origin of virulence in pathogenic fungi. Adv. Exp. Med. Biol. 2012, 710, 1-10. [PubMed]

74. Chrisman, C.J.; Alvarez, M.; Casadevall, A. Phagocytosis of Cryptococcus neoformans by, and nonlytic exocytosis from Acanthamoeba castellanii. Appl. Environ. Microbiol. 2010, 76, 6056-6062. [CrossRef] [PubMed]

75. Nielsen, K.; De-Obaldia, A.L.; Heitman, J. Cryptococcus neoformans mates on pigeon guano: Implications for the realized ecological niche and globalization. Eukar. Cell. 2007, 6, 949-959. [CrossRef] [PubMed]

76. Litvintseva, A.P.; Carbone, I.; Rossouw, J.; Thakur, R.; Govender, N.P.; Mitchell, T.G. Evidence that the human pathogenic fungus Cryptococcus neoformans var. grubii may have evolved in Africa. PLoS ONE. 2011, 6, e19688. [CrossRef] [PubMed]

77. Ruenwai, R.; Cheevadhanarak, S.; Laoteng, K. Overexpression of acetyl-CoA carboxylase gene of Mucorrouxii enhanced fatty acid content in Hansenula polymorpha. Mol. Biotechnol. 2009, 42, 327-332. [CrossRef]

78. Vorapreeda, T.; Thammarongtham, C.; Cheevadhanarak, S.; Laoteng, K. Alternative routes of acetyl-CoA synthesis identified by comparative genomic analysis: Involvement in the lipid production of oleaginous yeast and fungi. Microbiology 2012, 158, 217-228. [CrossRef]

79. Zan, X.; Tang, X.; Chu, L.; Zhao, L.; Chen, H.; Chen, Y.Q.; Chen, W.; Song, Y. Lipase genes in Mucor circinelloides: Identification, sub-cellular location, phylogenetic analysis and expression profiling during growth and lipid accumulation. J. Ind. Microbiol. Biotechnol. 2016, 43, 1467-1480. [CrossRef]

80. Li, Z.; Sun, H.; Mo, X.; Li, X.; Xu, B.; Tian, P. Overexpression of malic enzyme (ME) of Mucor circinelloides improved lipid accumulation in engineered Rhodotorula glutinis. Appl. Microbiol. Biotechnol. 2013, 97, 14927-14936. [CrossRef]

(C) 2020 by the authors. Licensee MDPI, Basel, Switzerland. This article is an open access article distributed under the terms and conditions of the Creative Commons Attribution (CC BY) license (http://creativecommons.org/licenses/by/4.0/). 